$11-2003$

\title{
Changing District Culture and Capacity: The Impact of the Merck Institute for Science Education Partnership
}

Thomas B. Corcoran

University of Pennsylvania, tomc@gse.upenn.edu

Nancy Lawrence

Follow this and additional works at: https://repository.upenn.edu/cpre_researchreports

Part of the Educational Leadership Commons, Educational Methods Commons, Education Policy Commons, and the Science and Mathematics Education Commons

\section{Recommended Citation}

Corcoran, Thomas B. and Lawrence, Nancy. (2003). Changing District Culture and Capacity: The Impact of the Merck Institute for Science Education Partnership. CPRE Research Reports.

Retrieved from https://repository.upenn.edu/cpre_researchreports/41

View on the CPRE website.

This paper is posted at ScholarlyCommons. https://repository.upenn.edu/cpre_researchreports/41

For more information, please contact repository@pobox.upenn.edu. 


\title{
Changing District Culture and Capacity: The Impact of the Merck Institute for Science Education Partnership
}

\author{
Abstract \\ In 1993, Merck \& Co., Inc. began an endeavor to make a significant and visible commitment to improving \\ science education by creating the Merck Institute for Science Education (MISE) and supported the new \\ venture with a 10-year, \$20-million financial commitment. From its inception, MISE had two goals: to raise \\ the interest, participation, and performance of public school students in science, and to demonstrate to \\ other businesses that direct, focused involvement would hasten the improvement of science teaching and \\ learning in the public schools. MISE initiated its work by forming partnerships with four public school \\ districts - Linden, Rahway, and Readington Township in New Jersey, and North Penn in Pennsylvania - \\ where Merck has major facilities. \\ CPRE was contracted by MISE in 1993 to document the implementation of the initiative and assess its \\ impact on districts, schools, classrooms, and students. Throughout the evaluation, CPRE conducted \\ interviews with teachers, instructional leaders, and district personnel; surveyed teachers; developed case \\ studies of schools; and examined student achievement data in order to provide feedback on the progress \\ of the MISE Partnership \\ Disciplines \\ Educational Leadership | Educational Methods | Education Policy | Science and Mathematics Education \\ Comments \\ View on the CPRE website.
}




\title{
Changing District Culture and Capacity: The Impact of the Merck Institute for Science Education Partnership
}

\author{
Tom Corcoran \\ Nancy Lawrence \\ CPRE Research Report Series \\ RR-054
}

November 2003

Consortium for Policy Research in Education

University of Pennsylvania Graduate School of Education 



\section{Contents}

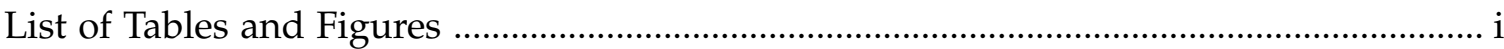

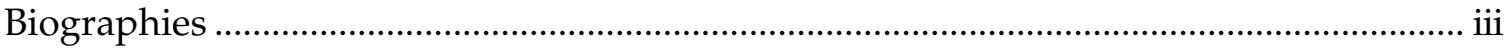

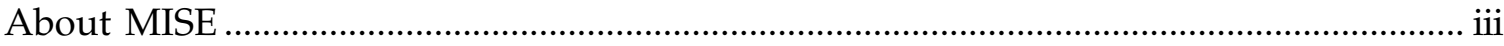

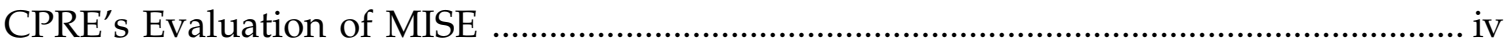

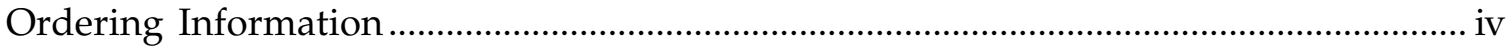

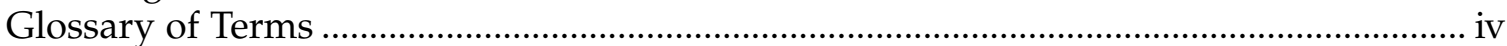

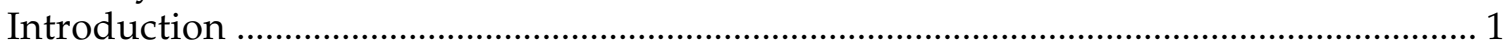

The Role of the School District in Instructional Improvement ........................................ 3

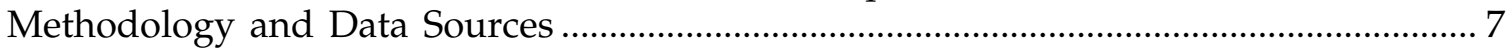

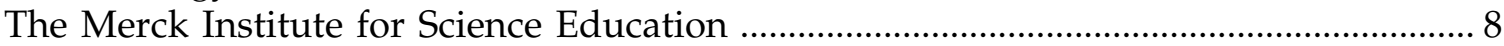

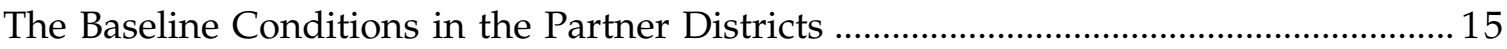

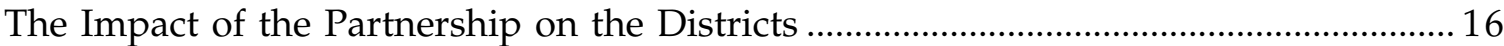

Leadership Committed to Improving Teaching .......................................................... 17

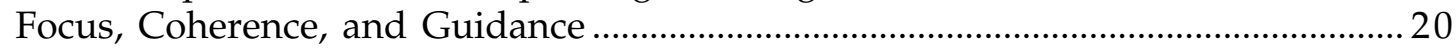

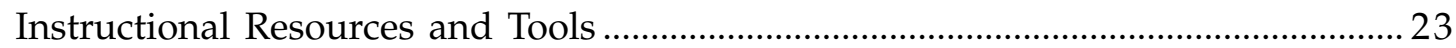

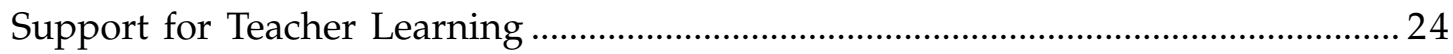

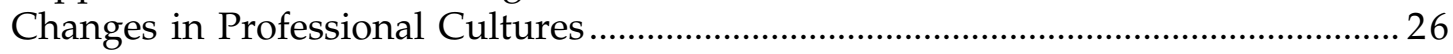

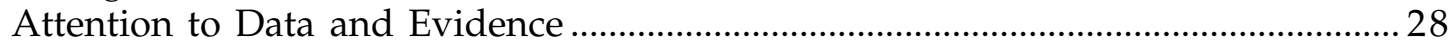

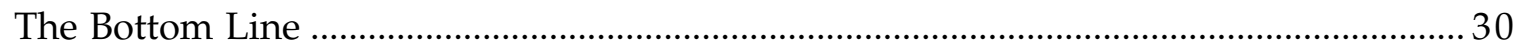

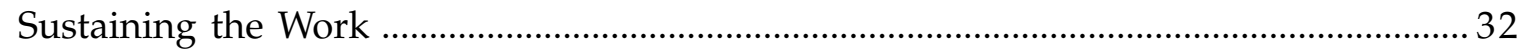

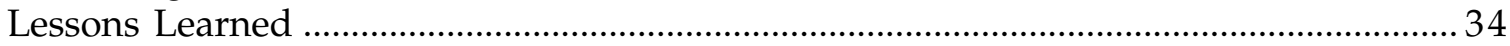

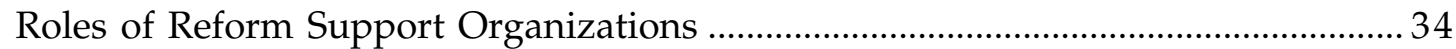

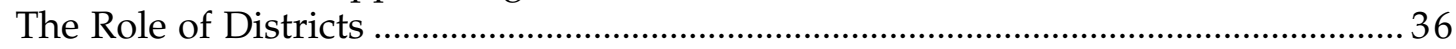

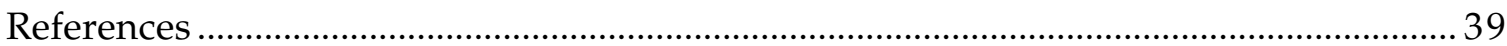

Appendix A. Annual Reports on CPRE's Evaluation of the Merck Institute for Science Education ............................................................................................ 43

Appendix B. Additonal Publications about the Merck Institute for Science

\section{List of Tables and Figures}

Table 1. Enrollments and Grade Spans of the Partner Districts, 1993-1994 and 2000-2001

Table 2. Minority Enrollments and Poverty in the Partner Districts, 1993-1994 and 2000-2001

Table 3. Comparisons of K-6 Science Modules Used District-wide, 1994-1995 and 2002-2003

Table 4. Peer Teacher Workshops, 1996-2002 


\section{Biographies}

Tom Corcoran is co-director of the Consortium for Policy Research in Education (CPRE). Prior to joining CPRE, Corcoran served as the education policy advisor for New Jersey Governor James Florio, director of school improvement at Research for Better Schools, and director of evaluation and later chief-of-staff of the New Jersey Department of Education. His research interests include the use of research to inform policy and practice in public education, the efficacy of different approaches to professional development, the effectiveness of whole-school reform, the impact of changes in work environments on the productivity of teachers and students, and the factors affecting the effectiveness of scaling-up strategies.

Nancy R. Lawrence is an independent research consultant specializing in the areas of education reform and policy. She received her Ph.D. in Education Foundations and Policy from the University of Colorado in 1994. In 1999, she started work on CPRE's evaluation of the Children Achieving reform in Philadelphia, PA. Lawrence continues to work with CPRE on several projects, including the evaluation of the Merck Institute for Science Education's efforts to increase students' understanding of science through changing teachers' practices, and an evaluation of a comprehensive school reform model. Prior to her work with CPRE, Lawrence worked at the Institute for Research on Learning in Palo Alto, CA.

\section{About MISE}

In 1993, Merck \& Co., Inc. began an endeavor to make a significant and visible commitment to improving science education by creating the Merck Institute for Science Education (MISE) and supported the new venture with a 10-year, \$20-million financial commitment. From its inception, MISE had two goals: to raise the interest, participation, and performance of public school students in science, and to demonstrate to other businesses that direct, focused involvement would hasten the improvement of science teaching and learning in the public schools. MISE initiated its work by forming partnerships with four public school districts - Linden, Rahway, and Readington Township in New Jersey, and North Penn in Pennsylvania - where Merck has major facilities. To learn more about MISE, visit www.mise.org. 


\section{CPRE's Evaluation of MISE}

CPRE, based at the University of Pennsylvania, was contracted by MISE in 1993 to document the implementation of the initiative and assess its impact on districts, schools, classrooms, and students. Throughout the evaluation, CPRE conducted interviews with teachers, instructional leaders, and district personnel; surveyed teachers; developed case studies of schools; and examined student achievement data in order to provide feedback on the progress of the MISE Partnership.

\section{Ordering Information}

Copies of this report are available for $\$ 5.00$ each. Prices include book-rate postage and handling. Make checks payable to Trustees of the University of Pennsylvania. Sorry, we cannot accept returns, credit card orders, or purchase orders. Sales tax is not applicable. To obtain copies, write:

CPRE Publications

Graduate School of Education

University of Pennsylvania

3440 Market Street, Suite 560

Philadelphia, PA 19104-3325

Quantity discounts are available. For more information, please call (215) 573-0700.

\section{Glossary of Terms}

Merck Institute for Science Education Partnership - Created in 1993 by Merck \& Co., Inc., MISE began a 10-year commitment to the goal of raising student interest, participation, and performance in science. MISE formed partnerships with school districts in Linden, Rahway, and Readington Township in New Jersey, and North Penn in Pennsylvania.

Leader Teacher Institute (LTI) - Launched in 1995 to provide intensive professional development to a select group of teachers from each partner school over a three-year period. These teachers would then become the Leader Teachers within their schools.

Leader Teacher - Selected teachers who attended LTIs and worked with new teachers by orienting them to the new module-based science curriculum and provided instructional guidance and support.

Peer Teacher Workshops (PTWs) - Launched by MISE in 1996, PTWs provided professional development opportunities open to all K-8 teachers in an effort to engage more teachers in science reform. PTWs were open for voluntary enrollment and each was led by a team consisting of a combination of Leader Teachers, content specialists, instructional specialists, and classroom teachers.

Principals' Institutes - MISE offers Principals' Institutes to make sure that principals are remaining informed about, and support, inquiry-based instruction and other aspects of the reform process. 


\section{Introduction}

Local school districts are uniquely American institutions. While the federal constitution grants full responsibility for public education to the states, and this responsibility is reflected in state constitutions, by tradition in most states, considerable authority over public schools rests with local boards of education and with the school administrations that they appoint and govern. Although states have become increasingly active in education policymaking during the past two decades and are exercising more authority over schools, the custom of local control acts as a serious constraint on state activism in public education. School districts are situated between state authorities and the schools, and they not only interpret and buffer state policies and initiatives, they also have the authority to make policy for schools. Thus, local policies, priorities, and capacities continue to exert powerful influences on teaching and learning, on the selection and implementation of reforms, and, therefore, on the improvement of academic outcomes. By and large, Americans are happy with this governance structure and supportive of their local public schools.

However, in recent years, some policy analysts and reformers have argued that public school districts, particularly those that are large and urban, are dysfunctional institutions lacking the capacity to lead, design, and implement muchneeded improvements, and, in fact often obstruct needed reforms (Chubb \& Moe, 1990; Hess, 1999; Hill \& Celio, 1998). Although much of the criticism of school districts has focused on large school systems, critics imply that many of the nation's 16,000 school districts are ineffective bureaucracies. As a consequence, some public and private reform initiatives — for example, the development of charter schools and comprehensive school reform designs - have attempted to bypass the district governance structure to work directly with schools. In addition, during the past decade, national foundations and major education organizations have supported efforts to redesign the governance structure of public education (Annenberg Institute for School Reform, 2002; National Commission on Governing America's Schools, 1999). And, in several large cities, control of the schools has been transferred from elected boards of education to mayors or school commissions appointed by mayors (Kirst, 2002).

Under increasing public pressure to improve the performance of the public schools, and now with the No Child Left Behind legislation, a statutory requirement to do it on schedule, state and local policymakers are desperately searching for ways to improve academic performance. Motivated by highly visible successes in Community District \#2 in New York City, Houston, and a handful of other districts, and frustrated with the slow pace of school-by-school reform strategies, reformers and researchers have begun to ask how school districts can be transformed into effective agents of improvement (Elmore \& Burney, 1997; Hightower, Knapp, Marsh, \& McLaughlin, 2002; McAdams, 2002). A small, but growing, research literature describes the characteristics of districts that appear to have successfully implemented instructional reforms and raised student achievement. Much of this literature focuses on how the professional culture of a school district - the rules, roles, and relationships - affects its capacity to improve instruction. Researchers have concentrated on large urban school systems because of their endemic performance problems. Less attention has been directed to other public school districts.

Another development in the past two decades has been the emergence of numerous public and private organizations dedicated to the improvement of the 
public schools. Referred to as "intermediaries" or reform support organizations, some of them play primarily advocacy roles, seeking to pressure systems to improve their performance or organize public and political support for the schools, while others offer technical assistance to the schools. The increasing investments in school reform and professional development have produced a market for the services of these organizations, but some have been created as vehicles for making investments in school reform external to the district bureaucracies. The role of these reform support organizations has not been carefully examined. The Annenberg Institute for School Reform (2003a) conducted a review of research on such organizations. ${ }^{1}$ The reviewers found little more than anecdotal evidence about the effectiveness of these external partners, but identified the keys to building effective partnerships with school districts as trust, need, local roots, and credibility. Reform support organizations such as the Bay Area School Reform Collaborative and the Boston Plan for Excellence are sponsoring external evaluations. In the near future, it may be possible to conduct comparative analyses of these evaluations to determine what makes these organizations effective. For example, are there particular entry strategies, aspects of their relationships with school systems, or improvement strategies that make some of these external organizations more effective than others?

With this report, we hope to contribute to the discussion of the roles of school districts and reform support organizations in improving teaching and learning by examining the cases of four districts

\footnotetext{
${ }^{1}$ Reform support organizations are external to school systems and seek to stimulate and/or support efforts by school districts to improve their effectiveness. They may be public, private, or non-profit entities. For a discussion of the characteristics and functions of reform support organizations, see Annenberg Institute for School Reform (2003b).
}

that have worked closely for more than a decade with a business-sponsored reform support organization, the Merck Institute for Science Education (MISE). The Consortium for Policy Research in Education (CPRE) has studied the collaboration between MISE and these four districts for a decade. With a sample of only four districts, and a reform strategy focused exclusively on science and mathematics, our data may not warrant sweeping generalizations about how school districts should be supported or redesigned to improve instruction. On the other hand, we have had a rare opportunity to observe and track these relationships over a long period of time, and to document the changes that have occurred from the classroom to the central office. Based on this longitudinal perspective, we feel that our findings offer some lessons both for those interested in the development of reform support organizations and in the design of system-wide instructional improvement initiatives. We also believe that our findings contribute to the development of a theory of district improvement by identifying and validating some of the factors contributing to enhanced district capacity to carry out improvements in teaching. Finally, we offer an encouraging existence proof demonstrating that it is possible to intentionally enhance the capacity of local school districts.

We begin by examining the literature on the district role in instructional improvement. Then, we briefly describe the work of MISE and its partner school districts in New Jersey and Pennsylvania, and the impact that this Partnership has had on the four districts. Finally we offer some lessons drawn from this experience, and a framework for thinking about the development of district capacity to support instructional change. 
The Role of the School District in Instructional Improvement

Until recently, researchers have neglected the roles played by districts in improving teaching and learning. They have concentrated on how specific characteristics of schools are related to improvements in teaching and learning. However, impatience with one-school-ata-time approaches to school reform has generated greater interest in system-wide reforms and in the roles that central offices might play. As a consequence, there is a growing literature on the role of school districts in instructional improvement.

Some of these studies have examined specific aspects of districts that might explain variations in observed performance or patterns of improvement. For example, early work by Murphy and Hallinger $(1986,1988)$ examined the role of superintendents in the improvement process and concluded that stability of leadership and focus were key factors in district performance. Firestone (1989) concluded that districts with strong professional communities in their central offices were more effective at using state reform efforts to leverage their own reform agendas.

Following the approach used in effective schools research, some studies have compared the characteristics of improving districts with those that are not making progress. Rosenholtz (1989) compared "moving" districts with "stuck" districts and concluded that the differences were due to the presence of a strong focus on instruction, policy and programmatic coherence, good communications, and good supports for teachers. These conditions tended to build teacher commitment and sense of efficacy, and produced improved teaching and student performance.
Researchers studying the implementation of the New American Schools comprehensive reform models reached similar conclusions. They found that district leadership was a critical variable in successful implementation of the school designs and that a clear focus on results, a limited reform agenda, wellaligned policies, support for professional development, and adequate resources for instruction, all contributed to district success at implementing comprehensive school designs. Conversely, they found that reforms were less likely to succeed when district leadership was unstable, there was distrust between the central offices and the schools, schools had little autonomy, and resources were limited (Berends, Chun, Schuyler, Stockly, \& Briggs, 2002; Berends, Kirby, Naftel, \& McKelvey, 2001; Bodilly, 1998; Kirby, Berends, \& Naftel, 2001).

A CPRE study of 22 districts in eight states concluded that districts were playing significant roles in shaping improvement activities in schools (Massell, 2000). The strategies being used by districts varied, and included interpreting and using data, building teacher knowledge and skill, aligning curriculum and instruction with standards and assessments, and targeting interventions on low-performing schools. While some other strategies were observed, these were the most common ones being used. While most districts used all of these strategies to some degree, districts tended to place particular emphasis on one or two "lead" strategies.

In a study of the implementation of state-initiated reforms in mathematics and science in nine Michigan districts, Spillane (1996) found that central office staff played critical roles in the implementation of state policies. What was implemented, and the effectiveness of implementation, varied depending on how district administrators interpreted state policies, and on how these interpre- 
tations were transmitted to teachers. The transmission strategies selected depended in large part on the theories held by central office staff about teacher learning (Spillane, 2002). Spillane found that these theories varied, and he categorized them as behaviorist, situated, or cognitive. The behaviorists preferred to have experts "deliver" new knowledge to teachers, and they often failed to recognize that teacher learning might depend on the prior knowledge and experience of the teachers. Those holding a situated perspective viewed learning as a social experience, and teachers as active learners. They used networks and study groups led by teacher leaders as central strategies for professional development. District leaders categorized as holding the cognitive perspective believed that teacher learning was enabled by reflection on their practice, and that teachers needed opportunities for reflection and access to new knowledge. The behaviorist view, and the training paradigm derived from it, were prevalent in the districts studied by Spillane. However, Spillane's evidence raises concerns about the efficacy of this approach for reforms in mathematics instruction that require fundamental changes in practice.

Well-documented case studies of district change are rare. It is not surprising, therefore, that a series of studies conducted in Community District \#2 in New York City have been given considerable attention. The district gained a national reputation by carrying out instructional reforms in literacy and mathematics and making sustained gains in student achievement. The studies describe the role that the central office played in initiating, scaling up, and supporting instructional improvement (Elmore \& Burney, 1997, 1999; Resnick \& Harwell, 2000). The district adopted a clear vision of good practice in literacy instruction, mobilized its resources to focus on its enactment, and sustained its focus over a number of years. District leaders worked with principals and teachers to build professional cultures in the schools that embraced the vision of good literacy instruction, but also worked collaboratively to refine and revise it and continuously improve classroom practice. Subsequently, the district pursued the same strategy in mathematics. In both instances, the district used professional development to build and sustain professional learning communities in the schools that supported implementation of the desired practice but also generated new knowledge about effective teaching. Stein and D'Amico (2002) described how district leaders' stress on the importance of authenticity and social interaction for students influenced their approach to teacher learning. This led them to take a more situated approach to professional development that strengthened professional communities and supported continuous improvement of practice.

In a study of three reforming districts in California, McLaughlin and Talbert (2002) found that local leaders focused on the system as a unit of change, established a clear focus on teaching and learning, provided instructional support to schools, and adopted data-based accountability. To focus their systems on instructional reform, they established clear expectations, used strategic planning to build a shared commitment to goals and strategies, and established norms of inquiry that encouraged the development of a learning community in the central office. Their focus on teaching and learning meant fewer goals, clearer and more specific goals, and greater policy coherence. The provision of support to schools meant reorganization of the central office, increased investment in professional development, and more attention to principals.

David and Shields (2001) documented the efforts of seven urban districts to implement standards-based systemic reforms. Supported by The Pew Charitable Trusts, these districts attempted to implement ambitious standards, aligned 
assessments, and accountability systems. Tracking their efforts over four years, David and Shields found that just putting these core components in place was not sufficient to bring about the changes in teaching and learning that standards advocates envision. Teachers needed more guidance than performance standards and tests provided; clear expectations about practice were also needed. High-stakes accountability systems tended to place the focus on raising test scores and undermined efforts to support ambitious teaching. The most successful districts set clear expectations about instruction as well as student performance, and backed these with intensive curriculum-based professional development and on-the-job assistance.

Two other recent reports describing the characteristics of improving districts support the findings from the David and Shields study (2001). Based on small numbers of interviews with leaders in districts that have made some progress, these two studies are, in effect, selfreports on the factors contributing to district success (Manpower Demonstration Research Corporation, 2002; Togneri \& Anderson, 2003). Manpower Demonstration Research Corporation compared four urban districts that had made considerable progress in the late 1990s with districts in which progress had been slower. They found considerable agreement among leaders in these improving districts about the attributes that accounted for their relative success. The faster-improving urban school districts were politically and organizationally stable over a prolonged period, and there was a consensus among leaders on the core reform strategies. These factors were seen as necessary prerequisites to meaningful change.
The four districts also:

- Focused on student achievement and set specific achievement goals for schools;

- Aligned curricula with state standards, and translated these standards into instructional practice;

- Adopted accountability systems that went beyond what the states had established in order to hold district leadership and building-level staff responsible for reaching the performance goals;

- Took steps to improve the quality of teachers and administrators in their lowest-performing schools;

- Adopted or developed district-wide curricula and instructional approaches rather than allowing schools to devise their own strategies;

- Supported these district-wide strategies through professional development and technical assistance;

- Drove reforms into the classroom by guiding and supporting instructional improvement in the schools;

- Committed themselves to data-driven decision-making and instruction;

- $\quad$ Prepared and encouraged teachers and principals to use assessment data to diagnose teacher and student weaknesses and make improvements;

- Began their reforms in the elementary grade levels instead of trying to fix everything at once; and

- Provided intensive instruction in reading and math to middle and high school students, even when it came at the expense of other subjects (Manpower Demonstration Research Corporation, 2002). 
In contrast, in the comparison districts, key stakeholders did not agree about district priorities or on strategies for reform. These districts lacked clear standards, achievement goals, timelines, or consequences linked to results. Their central administrations took little or no responsibility for improving instruction or creating a cohesive instructional strategy, and their policies were not strongly connected to teaching and learning in the classrooms. Their schools often received multiple and conflicting messages about curricula and instructional expectations that they were left to decipher on their own (Manpower Demonstration Research Corporation, 2002).

In the second of these snapshot studies, five districts with reputations for improving instruction were visited by teams from the Learning First Alliance. Although their scope of inquiry was somewhat narrower, their conclusions were similar to those reached by Manpower Demonstration Research Corporation (Togneri \& Anderson, 2003). They found the improving districts:

- Had acknowledged their poor performance and resolved to address it;

- Had adopted systemwide approaches to improving instruction;

- Had adopted clear visions of teaching and learning to guide instructional improvement;

- Made decisions based on data;

- Had adopted new approaches to professional development;

- Had redefined leadership roles; and

- Were committed to sustaining the work over time.
However, the Learning First Alliance team also found that the five improving districts faced serious challenges in sustaining their improvement efforts. Among the challenges were lack of time and funding, adapting organizational structures to new approaches to instruction and professional development, and implementing reforms in high schools.

Based on this research literature, what might we conclude? First, there is not strong empirical evidence supporting the notion that districts can develop the capacity to make sustained improvements in teaching and learning. Second, the literature does not offer a well-specified theory of action, but it suggests some key factors that affect a school district's capacity to engage in sustained efforts to improve instruction. These key factors might include:

- Leadership focused on results and committed to instructional improvement;

- A focused strategy for improving instruction that is sustained over multiple years;

- The alignment of critical policies to guide practice and to support improvement;

- The provision of resources to implement the reforms;

- Clear expectations about classroom practice;

- Support for teacher learning and adequate investments in professional development;

- Development of communities of practice in central offices and schools that share a common vision of good practice and beliefs about teaching and learning; and 
- The use of data and evidence to drive decisions and revise strategies.

These findings provide an initial framework for discussing the role of the district and what capacities districts need to lead and implement improvements in teaching and learning. They are consistent with a larger literature on organizational effectiveness and job performance that identifies five general variables that explain most of the variation in the performance of schools. These are the quality of leadership; the knowledge and skills of teachers and other staff; the quality and quantity of the resources available for teaching, including staffing levels and instructional time; beliefs about teaching and learning; and the quality and coherence of organizational guidance (Argote, 1999; Bacharach \& Barnberger, 1995; Corcoran, 1995; Corcoran \& Goertz, 1995; DarlingHammond, 1993; Elmore, 1993; Goertz, Floden, \& O'Day, 1995; McLaughlin \& Talbert, 1993; Rowan, 1996).

However, these findings rest largely on correlations among measurable organizational attributes and the degree of implementation of specific practices or improved performance. This begs the question of whether these conditions actually cause higher productivity and improvement. Causality is frequently assumed or implied in the literature even though the findings do not support such claims. The existing literature also provides little guidance on how to create these conditions in schools and districts. Can these conditions be created intentionally? How important are reform support organizations in this process? If the conditions are created, do they produce significant and sustained gains in achievement? These are important questions for policymakers interested in improving the performance of public school systems. If the answers are that these capacities cannot be developed, or are too difficult or expensive to put into place, policymakers might be well advised to turn to the restructuring solutions offered by the critics of public school districts. Unfortunately, the research literature does not provide definitive answers to these questions.

Few researchers have had the opportunity to track changes in school districts over time. The CPRE evaluation of MISE and its four partner districts offers a rare, longitudinal look at the efforts of a reform support organization to alter the capacities of its partner districts, and the findings suggest some answers to the questions raised earlier. What is MISE, and how has it sought to alter local capacity? In the next two sections, we describe the CPRE evaluation of MISE and its partnership with four school districts. Then we use the framework of key factors listed above to examine the changes that occurred in the four districts in the areas that appear to be critical to district capacity to support improvements in teaching.

\section{Methodology and Data Sources}

The data for this report come from a longitudinal evaluation of a business-led partnership seeking to improve the quality of science instruction in grades K8 in four school districts (three in New Jersey and one in Pennsylvania). For a decade, CPRE has documented the work of MISE, and examined the elaboration, evolution, and efficacy of its theory of action. CPRE also conducted the evaluation of the Partnership, which was the collaborative formed by MISE and its four partner districts and which was funded in part by the National Science Foundation (NSF). CPRE documented the quality and impact of the professional development and technical assistance provided by MISE and its partners, and changes in district and school policy, school culture and organization, curriculum and classroom practice, and student outcomes. Each year, CPRE staff conducted inter- 
views with district, school, and MISE staff; observed teachers, planning, and professional development; and from 1996 to 2001, administered annual districtwide surveys of teachers and school administrators. There was a consistent focus on the quality of professional development and its impact on teaching practice and student performance (see Corcoran, McVay, and Riordan, in press). Each year, interviews were conducted with professional development leaders, teachers who participated were surveyed, a small sample of the participants were interviewed and observed, and a set of case study schools was visited every two years.

From 1996 to 2001, MISE and its partners had a Local Systemic Change (LSC) grant from NSF, and the CPRE evaluation was partially funded by NSF. During those years, CPRE cooperated with Horizon Research, Inc. (HRI), which was the national evaluator of the LSC program. HRI provided some of the interview protocols, the observation protocol, and the teacher survey. HRI also drew annual samples of teachers to be observed. However, with support from MISE, CPRE broadened the HRI data collection activities to collect survey information from all teachers and administrators in the four districts and to conduct additional observations and interviews. On average, each year, 600-
700 teachers completed the HRI surveys and responses ranged from $70-85 \%$. In addition, between 20-100 classroom observations were completed, and 50-100 interviews were conducted each year.

CPRE produced annual reports on the work of MISE with the four partner districts. In 2003, CPRE issued a set of reports that took a longitudinal perspective on professional development, instructional leadership, and the overall impact of MISE. ${ }^{2}$

\section{The Merck Institute for Science Education}

MISE is a not-for-profit organization, founded in 1993 by Merck \& Co., Inc., and funded in part by the corporation's foundation. Its primary mission is to demonstrate that virtually all students can reach a high level of scientific literacy. The idea of MISE was spawned in the euphoric period of the early 1990s when the nation was embracing national goals for education, and national and state content and performance standards were being developed in the core subject areas.

With a 10-year commitment from the corporation, MISE formed partnerships in 1993 with four public school districts Linden, Rahway, and Readington Township in New Jersey, and North Penn in

\section{Table 1. Enrollments and Grade Spans of the Partner Districts, 1993-1994 and 2000-2001}

\begin{tabular}{lcccc}
\hline Kistrict & $\begin{array}{c}\text { K-8 Enrollment } \\
1993-1994\end{array}$ & $\begin{array}{c}\text { K-8 Enrollment } \\
\text { 2000-2001 }\end{array}$ & Grade Span & $\begin{array}{c}\text { \# of Schools, } \\
\text { Grades K-8 } \\
\text { 2000-2001 }\end{array}$ \\
\hline Linden & 3,405 & 4,204 & K-12 & 10 \\
North Penn & $7,759 *$ & 10,534 & K-12 & 14 \\
Rahway & 2,229 & 2,747 & K-12 & 5 \\
Readington & 1,473 & 2,113 & K-8 & 4 \\
\hline
\end{tabular}

\footnotetext{
* This figure represents grades K-7 as eighth graders attended the high school.
}

${ }^{2}$ The annual reports are listed in Appendix A and the focused longitudinal reports are listed in Appendix B. 
Table 2. Minority Enrollments and Poverty in the Partner Districts, 1993-1994 and 2000-2001

\begin{tabular}{lcccc}
\hline & \% Minority & \% Minority & $\begin{array}{c}\text { \% Eligible for } \\
\text { Free and } \\
\text { Reduced-price } \\
\text { Lunch } \\
\text { District }\end{array}$ & $\begin{array}{c}\text { \% Eligible for } \\
\text { Free and } \\
\text { Reduced-price } \\
\text { Lunch }\end{array}$ \\
\hline Linden & $1993-1994$ & $2000-2001$ & $1993-1994$ & $2000-2001$ \\
North Penn & 46.6 & 61.0 & 30.0 & 43.5 \\
Rahway & 12.7 & 18.3 & NA & 10.5 \\
Readington & 47.4 & 65.0 & 22.0 & 30.0 \\
\hline
\end{tabular}

Pennsylvania - towns in which Merck has facilities and a history of supporting local science initiatives. MISE provided both funding and technical assistance to the districts, and in exchange, the districts agreed to give priority to science, undertake systemic reforms to support improvements in science teaching and learning, and invest in a shared reform agenda. In 1995, the five partners successfully competed for funding from NSF. In 2003, Merck \& Co. reaffirmed its commitment to support MISE and extended its funding for another five years.

The four partner districts vary in both size and demographics. Table 1 displays basic information about the enrollment and organization of the four districts. Three of the districts are small; two of these districts are small urban communities, and one is a rural K-8 district. The larger district is a suburban district outside of Philadelphia. Table 1 also shows the change in enrollment from 1993-1994 to 2000-2001. All four districts experienced considerable growth in enrollment during this period.

Table 2 displays data on minority enrollment and the percentage of students eligible for free and reduced-price lunch. Here again, there is variation as the partner districts range from bluecollar towns in New Jersey to rural and suburban enclaves. The data show the increases in minority enrollment and suggest increases in the number of students living in poverty in both Linden and Rahway.
MISE can be best described as a reform support organization (Annenberg Institute for School Reform, 2003b). ${ }^{3}$ Created by interests external to public school systems to support school reform, organizations like MISE seek to leverage and support changes within public school systems. They vary widely in their governance structure, mission, funding, size, and strategy. Like MISE, other reform support organizations such as the El Paso Collaborative for Educational Excellence, the Success for All Foundation, the Bay Area School Reform Collaborative, and the Boston Plan for Excellence have achieved national reputations for their school reform work. Only recently, however, have researchers begun to report on their effectiveness. These organizations work across the boundaries of educational systems, and are neither "of" the system nor wholly outside it. Serving as catalysts for changes, they receive resources from various public and private sources. They are presumed to be free of the interests and political pressures that are believed to obstruct reforms initiated from within school systems. The creation of such organizations has become a popular strategy for private groups seeking to promote public school reform.

\footnotetext{
${ }^{3}$ Reform support organizations are defined as "public, quasi-public, and private non-profit organizations that seek to engage, or are engaged by school districts in efforts at systemic reform" (Kronley \& Handley, 2002, p. 3).
} 
The Vision. A vision of good science instruction has guided the MISE Partnership. This vision holds that inquiry must be an integral and regular part of the classroom experience of all students. By using inquiry methods, science teaching and learning imitate the methods used by scientists to understand the natural world. The assumption is that when students are engaged in scientific inquiry, they develop greater interest in, and deeper understanding of, science than would be possible through conventional instructional approaches. MISE contends that inquiry helps students develop the skills and habits of mind needed for scientific work.

So, for MISE, the most important instructional experiences are investigations that challenge students to observe, question, hypothesize, test, and defend their explanations of natural phenomena. To teach in this manner, teachers must have a firm grasp of the subject matter so they can encourage students to ask critical questions and help them seek meaningful answers, and an equally firm grasp of pedagogy and classroom management so they can create active classroom environments that encourage student inquiry.

Recognizing that many teachers in the four partner districts did not possess the knowledge or skills needed to design and guide scientific inquiry, MISE staff believed that building this capacity would require long-term support as well as significant changes in curriculum, instructional materials, assessment, scheduling, and district policies. To make these changes, policymakers and administrators had to give science greater priority and invest more in order to provide teachers with the time, support, training, and materials required. Thus, from
MISE's initial vision of good science teaching stems a comprehensive reform agenda that touches most aspects of a school system.

The Strategy. From its inception, MISE took a systemic approach to the improvement of teaching and learning in the partner districts, seeking to persuade its partners to develop coherent and aligned policies and practices that would foster and support the continuous improvement of science instruction. Understanding that simply providing funds or offering professional development would not bring about the changes in science teaching that they sought, MISE's strategy called for fundamental changes in the professional cultures of the districts and in their capacity to support and sustain reformed classroom practice. MISE's theory of action is composed of the following nine components, not as sequential steps in a linear model of change, but rather as interactive, mutually reinforcing processes:

- Development of a shared vision of reformed practice among district and school leaders that is consistent with state and national standards;

- Development of a culture of distributed leadership and a professional community around science to promote the continuous improvement of science teaching;

- Development of new curriculum frameworks and assessments for science to guide practice;

- Adoption of tested instructional materials compatible with the standards and inquiry-centered instruction; 
- Provision of high-quality learning opportunities for teachers to support the effective enactment of the new curriculum and inquiry-centered instruction;

- Building of communities of practice in and across the schools to support enactment of the curriculum, sharing of experience and knowledge, attention to results, and reflection and revision;

- $\quad$ Alignment of other policies and procedures (assessment, teacher evaluation, materials management, and most importantly professional development) with the new vision and the support elements described above;

- Use of data to set strategic priorities, revise policies and programs, and guide teaching; and

- $\quad$ Sustaining the collaborative work until these components are institutionalized in the district.

The consistency of this theory of action with the factors identified by researchers as critical to successful district initiatives to improve teaching and learning is striking. MISE set out to create the very conditions and capacities that researchers have identified as critical characteristics of districts that have successfully carried out system-wide reforms.

The Partnership. Establishing an effective partnership between a large international corporation and four public school systems was not easy. Perceived differences in prestige, status, power, and resources between Merck and the districts were barriers to collaboration. Reflecting on the early days of working with MISE, district leaders and staff recalled a sense of imbalance in the status and power among the five partners. A district administrator describing the early phase of the MISE Partnership said, "The perception was pervasive that MISE was calling the shots." As a result, there was some resentment and resistance among central office staff in the first few years of the Partnership. However, this was not the case among teachers who felt respected by MISE staff from the beginning and were appreciative of how they were treated and the rich professional development that was provided.

However, MISE wanted a full partnership with the districts rather than just another funded project. Its goal was to build the capacity of the districts to sustain the work, and this meant district leaders had to understand it and own it. By pursuing collaborative decisionmaking and gradually shifting responsibility to the districts, over time MISE brought about significant changes in the nature of the collaboration. Working to bid on an LSC grant from NSF moved the relationships with the districts closer to MISE's vision of collaboration.

The Partnership's Advisory Committee was a key mechanism for establishing collaboration and building district ownership. Each district was represented on the Committee by a team composed of the superintendent, district curriculum personnel, at least two Leader Teachers, and one or more principals. Some members rotated annually to foster broader participation in Partnership decisionmaking. These district teams took on responsibilities for local planning, and they served on cross-district teams convened to explore issues related to resource allocation, professional development, assessment, and curriculum.

The Advisory Committee was initially simply a vehicle for MISE to share its agenda, gain local commitment to plans for the Partnership, and receive feedback from the districts. However, it quickly evolved into an open forum on design and implementation. As the Partnership evolved, the Committee became a more active body, setting the direction and priorities for the Partnership. 
MISE provided funding to the districts throughout the life of the Partnership, and continues to do so. However, the districts also have invested time and money in the collaborative work. Almost all of the district leaders and staff interviewed in 1999 and 2001 emphasized the non-monetary benefits gained from the Partnership. They appreciated the funding, but they stressed that MISE had provided them and their districts with vision, focus, expertise, and continuity as well as funding. In their experience, most improvement initiatives had short life spans, lasting from one to three years, and then they were usually dropped to be replaced by another priority, agenda, or project. The Partnership had been unusual in its persistence, sustaining the focus on science instruction for a decade. MISE had given the four districts and their schools unprecedented time to implement and spread new curriculum materials and instructional strategies.

The Work of the Partnership. Here we offer a brief account of the Partnership's work over the past decade to give the reader a sense of its range and scope. More detailed reports on the activity of the Partnership can be found in the annual reports and in other analyses published by CPRE. ${ }^{4}$

Beginning in 1993, MISE established working partnerships with the four districts and sought good working relationships with key stakeholders in each district. In the first two years, MISE assisted the districts with the selection and purchase of new instructional materials for elementary science and supported local professional development activities. MISE helped local educators envision a new approach to science education by sponsoring their attendance at national conferences; exposing them to state-ofthe-art materials and national resources,

\footnotetext{
${ }^{4}$ Eight annual reports were published from 1995 to 2002. They are listed in Appendix A. Additional analyses of the effects of the Partnership's efforts are listed in Appendix B.
}

such as the National Science Resources Center; and encouraging them to visit classrooms in which challenging reformbased science instruction was taking place. MISE also opened a curriculum resource center, enabling staff in the partner districts to review and try out new instructional materials without purchasing them.

MISE staff soon realized that serious instructional reforms in the four partner districts would take considerably more time, resources, and commitment than they had anticipated. Many K-6 teachers lacked sufficient knowledge of science to make effective use of the new curriculum materials, and the districts lacked the capacity to provide the needed professional development and classroom support. While the four partner districts had increased their professional development opportunities for teachers during the first two years of their partnerships with MISE, these were generally afterschool workshops on how to use the new science kits. These sessions offered little opportunity for teachers to develop deeper understanding of high-quality science instruction or to practice use of inquiry methods. It was clear after the first year of the Partnership that a more activist approach would be required if MISE was to have a significant impact on the Partnership's 34 schools and nearly 1,000 teachers.

To meet this need, MISE designed an intensive professional development program to prepare teams of teachers in each school to lead science reform. Recognizing that there were differences among the four districts, MISE felt that a common experience would break down parochialism and build a common set of professional norms across the partner districts. In the summer of 1995, a threeyear program in science leadership, the Leader Teacher Institute (LTI), was launched, enrolling more than 140 teachers from 34 schools. The LTI offered a common professional development experience for small teams of teachers 
from each of the elementary and middle schools in the four districts and provided them with opportunities to deepen their knowledge of science, master the use of inquiry methods, and develop their leadership skills. The teachers were recruited by contacting school principals and sending out applications to the schools for distribution to teachers. A typical Leader Teacher team consisted of four teachers from different grade levels. MISE also worked with principals of all of the schools serving grades K-8 so that they would understand good classroom practice in science and make effective use of the Leader Teachers.

One year later, the Partnership received a major grant from NSF's LSC program. The primary objective was to provide 100 hours of high-quality professional development in science and mathematics to nearly $800 \mathrm{~K}-8$ teachers of science and mathematics from the four partner districts over five years. This required a different professional development strategy. Peer Teacher Workshops (PTWs), consisting of week-long summer institutes and follow-up sessions during the year, were designed to meet the requirements of the LSC grant. The PTWs were curriculum-based and quite focused. Most were intended to prepare teachers to use the new science modules being adopted by the partner districts, while others focused on new elementary and middle school mathematics curriculum and some addressed classroom assessment. MISE, district staff, and the Leader Teachers provided the participants with follow-up support.

In the summer of 1996, more than 160 teachers participated in the first PTW. The PTWs were designed and delivered by instructional teams composed of MISE staff, external consultants, and accomplished Leader Teachers from the districts. In this way, the PTW program enhanced local capacity for professional development as well as teachers' capacity to teach science.
The impact of the PTWs was positive from the start, but the observed changes in instruction were incremental. Participating teachers told CPRE researchers that they were more comfortable using the new instructional materials and most said that they were engaging students in inquiry. Encouraged by their supervisors and principals, and by what they heard from their colleagues, teachers signed up for the PTWs, and enrollments in the summer workshops grew rapidly. In 1997, nearly 200 regular and special education teachers participated, and by the summer of 2000, enrollments were close to 500. By 2001, the Partnership exceeded its goal of providing 100 hours of professional development to more than $800 \mathrm{~K}-8$ science and mathematics teachers.

Through the Leader Teacher initiative, MISE attempted to change the professional cultures in schools and provide supportive environments for the enactment of the knowledge and skills gained through the summer PTWs. MISE staff provided technical assistance and support for the Leader Teacher teams in each school. They provided training for school principals so they would know what to expect in science lessons, and could support the Leader Teachers and those attending the PTWs. The Leader Teachers demonstrated lessons on inquiry for their colleagues, mentored student teachers, assisted their colleagues in designing lessons, and worked with parents on family science programs, science fairs, and similar events.

In 1997, MISE broadened its reform agenda by addressing classroom assessment in science. Seventy-three teachers working in district study groups on assessment developed and refined performance assessment activities that were linked to specific curriculum modules. The performance assessments were reviewed by MISE staff and other experts and published by MISE. They were widely used by teachers in the partner districts. And, after extensive discussions, 
the Partnership adopted a plan for strengthening its approach to assessment in science. The plan had four components: Administration of a standardized science test, administration of standardized hands-on science performance tasks, use of district-wide performance tasks at multiple grade levels, and increased use of module-specific assessments to inform instruction. A significant step was taken in the 1999-2000 school year when two performance tasks adapted from the Third International Mathematics and Science Study (TIMSS) were administered in all third- and seventh-grade classrooms in the four partner districts. Teams of teachers worked with MISE staff to select, modify, and field test these tasks. Teachers were trained in their administration and in the interpretation of the results. This work has continued up to the present time, and has been expanded into grades 4 and 8 .

MISE also impacted district policy. With support and advice from MISE, the four districts upgraded their instructional resources for science and their systems for managing these materials. By 1996, all of the districts had adopted new science modules as the backbones of their K-6 science curriculums. All four districts drafted new science curriculum frameworks that were aligned with state and national standards and reflected the new instructional materials. MISE staff supported and guided this work, and the Leader Teachers played key roles in the development of the local frameworks. These new district science curriculum frameworks were approved by the local boards of education. By the 1997-1998 school year, the Partnership was having a broad impact on professional life and instructional policy in the four partner districts.

During these years, MISE worked with district teams that included central office curriculum leaders, principals, and Leader Teachers to develop strategic plans for improving science teaching. These action plans focused on curriculum and instruction, student achievement and participation, policies and practices, and parent and community support. District staff defined objectives and set benchmarks for each of these areas. They developed strategies and identified the resources and individuals necessary to meet their objectives. The planning process was not taken seriously at first as the districts had considerable experience producing meaningless plans for their respective state agencies. The MISE staff persisted, providing technical assistance and data, and giving feedback on the coherence and feasibility of the plans. Over time, this process encouraged districts to make better use of data and to think more systemically and coherently about the larger reform picture.

The four districts also worked together, breaking down the parochialism that so often characterized the cultures of local school systems, and sharing their expertise. They planned and delivered PTWs together. They worked on assessment together, especially the administration of the TIMSS performance assessments.

By the 2000-2001 school year, local teams of Leader Teachers and central office staff had assumed responsibility for much of the planning, design, and management of the summer workshop program. Teachers from the four partner districts were serving on the instructional teams, and teacher enthusiasm for these professional development experiences was strong. The local districts were also providing more of the financial support for the summer program. After the NSF funding ended in 2001, MISE continued its funding to the four partners, and the districts continued to support the summer PTWs and the in-school support.

This is not the end of this story. The work of the Partnership continues. MISE is now working with additional districts, 
but the association with the four original districts continues, and they seem determined and able to carry the work forward. The effectiveness of the Partnership in raising the status of science, developing teacher leadership, changing teachers' practice, and improving student performance in science has been described in detail elsewhere (Corcoran, 2003; Corcoran, McVay, \& Riordan, in press; Riordan, 2003). Here, we focus on the changes that have occurred in the districts and how these changes have made the districts more effective at leading, supporting, and sustaining instructional improvement.

\section{The Baseline Conditions in the Partner Districts}

In this section, we describe the conditions in the four districts when they first entered into relationships with MISE. In particular, we describe those dimensions of district organization, culture, and capacity that have been identified by researchers, and in MISE's theory of action, as critical to successful and sustained instructional improvement. These fall into the eight domains identified earlier in this report:

- Leadership committed to instructional improvement;

- $\quad$ Sustaining support for instructional reform over time;

- Coherent policies to provide focus and guidance;

- Instructional resources to support the desired practice;

- Setting clear expectations for practice;

- Support for teacher learning;

- Professional norms that support improvement of practice; and
- Use of data and evidence as a basis

for decision-making at all levels.

Focus, Leadership, and Policies.

Science was not a high priority in the four districts in 1993. Two of the districts had science supervisors, and all four were providing some professional development in science, but none had set standards in science and only one assessed performance in science. The district curriculum guides were outdated and ignored by many teachers. There was no state assessment in science in New Jersey or Pennsylvania, and the accountability systems focused on literacy and mathematics. Training in science was not considered in the hiring of elementary school teachers and many of the middle school science teachers were K-8 certified.

All four of the districts were affected by the constant changes in state policies and priorities, and by the fads of reform that swept over the profession. Thus, like most districts, they found it difficult to sustain a particular focus or strategy for improvement or provide support for it over multiple years. Rather, they tended to adopt a strategy, provide some training to get people started, and then move on to the next reform.

Instructional Resources, Expectation for Practice, and Support for Teacher Learning. MISE drew on the national standards in science and existing standards-based curriculum materials to help the districts develop a shared vision of good practice. The idea of guided inquiry or inquiry-centered instruction was at the core of the work and was the foundation for providing guidance about good science teaching.

Some commercially developed science modules were being piloted in the Readington and North Penn school districts. But these were being used in only a limited number of classrooms. There was considerable variation in the instructional resources available to 
teachers. To some extent, the quality of science resources in a classroom depended on a teacher's interest in science and longevity in the district. Many teachers had few resources beyond their textbooks. Some lacked the basics needed for inquiry-centered science. For example, some were in classrooms without running water.

The professional development opportunities in science varied. North Penn had an in-house professional development program, but for the most part, these opportunities consisted of one-day workshops. They were offering some training to the teachers who were piloting new science modules. In Rahway and Linden, large numbers of teachers were participating in a summer professional development program in science offered by Fairleigh Dickinson University. This two-year program encouraged the use of hands-on science. When teachers in the four districts were asked about the extent to which in-service training had affected the content and methods of their science instruction, almost $65 \%$ of the K-5 teachers in Rahway said it had exerted a great deal of influence. In Linden, North Penn, and Readington, only $25-30 \%$ of the teachers offered similar assessments of their professional development. It is not clear why Linden teachers reported such little impact as the district had hired science mentors to help other teachers improve their science instruction and had developed a network of teachers who were meeting to discuss and reflect on science instruction.

Professional Norms and Use of Data. In 1993, the teaching of science in grades $\mathrm{K}-8$ in the four partner districts was, for the most part, conventional. Science was, by and large, taught as a textbook subject, and it was allocated far less time and attention than literacy and mathematics. In many instances, it was taught as a supplement to the literacy program. The vast majority of teachers in Linden and North Penn told CPRE researchers that they almost always or often used textbooks for science instruction. In Readington and Rahway, however, a majority of the respondents indicated that they were making extensive use of other materials. These findings reflect differences in instructional philosophies and professional norms in the districts that had developed as a result of the availability of alternative instructional materials and professional development.

Little attention was given to student performance in science because only one district had system-wide data. There were no state science assessments. There were no systems in place for tracking students into high school to look at their coursetaking patterns. Neither district nor school leaders had any way of gauging how well students were doing in science.

In sum, in 1993, the four districts were rather typical in many respects, but there were signs of concern about science teaching and some recognition that better professional development was needed. Nevertheless, at least as far as science was concerned, the four districts fell short on the six dimensions of capacity identified as critical to improving instruction. They appeared to lack the capacity to launch and sustain focused, robust efforts to improve teaching.

\section{The Impact of the Partnership on the Districts}

How have the partner districts changed as a result of their partnership with MISE? What have been the mechanisms for bringing about these changes? In this section, we again use the dimensions of school districts identified earlier as a frame for examining what has changed in the partner districts, and for determining how these changes are linked to the activity of the Partnership. While we describe the changes one 
dimension at a time, in reality they overlap and interact. Changes in one area produce or support changes in another. The changes in the partner districts did not unfold in linear fashion with a clear starting point and sequence, but were multi-dimensional and complex as simultaneous initiatives and pressures in several areas reinforced one another, and produced momentum for sustained changes. This is not just a story about policies or programs although they are important parts of the story, but it is also a story about people and the cultures of work that were created when people were engaged, respected, and empowered through access to knowledge, skill, and opportunity.

\section{Leadership Committed to Improving Teaching}

In the early 1990s, priorities in the four districts came and went as superintendents, boards, and state policies changed, and the attention of local leaders was fragmented and distracted by short-run issues and multiple initiatives. The state accountability systems, particularly in New Jersey, generated pressure to improve performance in literacy and mathematics, but offered no incentives for making investments in long-term development of teachers' knowledge and skills. To the contrary, the assessment and accountability systems created incentives for districts and schools to find quick fixes - new programs, materials, or instructional strategies that would bring immediate improvement in test scores.

In general, local leadership was based on position power and was exercised hierarchically. Superintendents set the agendas. Principals set the priorities in schools, and to a large extent set the standards for good practice in their buildings. The four districts were characterized by the standard hierarchy with administrators occupying the "upstairs" of the system and teachers toiling "down- stairs." Communication across these levels was limited, and teachers had little voice in shaping either the priorities or the initiatives designed to address them. For the most part, they were viewed by board members and administrators as objects of improvement rather than sources of expertise about how to improve teaching.

How has district leadership changed? From interviews with district leaders and observations of district planning conducted over eight years, we have identified three major ways in which leadership has been altered by the Partnership. First, the Partnership changed the ways in which leadership was exercised by advancing the concept of distributed leadership in the districts and fostering the development of professional learning communities at both the district and school levels. Second, the Partnership reinforced these ideas about who could exercise leadership by fostering a new and profoundly important respect for the knowledge of expert teachers. And, third, in response to the requirements set by MISE, the districts adopted a strategic planning process that provided them with focus and ensured broad commitment to the goals. These changes had profound effects on how decisions are made in the four districts.

New Norms of Leadership. As indicated earlier, MISE envisioned the possibility that teaching could be so effective that teachers could virtually reach almost all children. This was a powerful and ultimately persuasive message, but one that had enormous implications for the responsibilities of district leaders and for the nature of leadership. As one central office staffer said:

[MISE has been] the biggest plus for the science program ever. The amount of professional development, leadership, guidance, purchase of materials. It's just something we wouldn't have been able to do. We would not have had that kind of 
vision. But it has also challenged us to take responsibility for the quality of teaching, to make sure that good teaching was going on in every classroom.

Transforming such a radical vision into practice required a willingness to learn about teaching and learning. While some of the required knowledge might be gained from external experts, MISE urged district leaders to reach out to accomplished teachers in their systems and engage them in dialogue about improving instruction. In this way, they fostered the development of strong professional leadership communities in the districts that linked the central office, the schools, and the teaching force. The work of the Partnership, and the demands made by MISE, forced those holding administrative positions to recognize that they needed the subject-matter and pedagogical expertise possessed by teachers. MISE modeled this distributive approach to leadership in its own work, and reinforced it by developing teacher leaders and encouraging them to insist on having a voice in professional decisions. Over time, a new model of leadership emerged in the districts, one based on knowledge and skill as well as position.

\section{Respect for Teaching and Teachers.}

The new approach to decision-making was accompanied by a profound change in how district administrators viewed teaching and teachers. Teaching was elevated in status by MISE. They viewed teaching as a demanding profession that required understanding of complex interactions among children, content, and instruction. Accomplished teachers were to be held in high regard and valued, and were to be viewed as leaders who possessed special knowledge. Through modeling these beliefs, acting on them, and pressuring local leaders to do likewise, MISE advocated a new view of teachers and teaching. These views began to permeate the district cultures and, over time, were embraced by the vast majority of district administrators. The interview data from 1994 and 2001 clearly reveal these changes. When asked about sources of expertise in 1994, less than a quarter of those interviewed mentioned teachers, but, in 2001, almost everyone did. Involving experienced teachers in decisions about curriculum and professional development is not a new idea, but actually taking their input seriously and involving it in the design of policy and programs is a shift. One superintendent said:

There is a recognition here that our job is to guide and support their work, not control it. We know that really good teachers understand teaching and learning better than many of us, and if we try to decide on what to do without engaging them, we make a mess of it. We are more collaborative now.

A veteran district administrator who had been active in the Partnership from its inception described the change "...as a revolution; teachers sit at the table as colleagues, and often take the lead in deciding what we are going to. This never would have happened 10 years ago." Yet another described the most significant benefit of the Partnership as the new confidence and knowledge of the teachers:

When people first hear of Merck, they think "money." Sure, it's been a financial help but more than that, it has developed our teachers' content knowledge, leadership, skills. They have changed, and the district is better for it.

This newfound respect for teaching and teachers can be directly attributed to MISE's insistence that teachers be involved in planning and professional development, and its preparation of Leader Teachers. These actions empowered many teachers to speak out on matters of teaching and learning. The Leader Teachers exercised this warrant in a number of ways, serving as mentors, leading school and district in-service days, planning and leading PTWs in their 
districts, and serving on science and mathematics curriculum and frameworks committees. Many have served on MISE's Advisory Committee, which brings together leadership groups from the four partner districts to discuss strategic issues and formulate policies and other reforms.

MISE's approach to professional development design and delivery served as a model for how a professional community could function. The districts, over time, became comfortable with this less hierarchal approach to decision-making, realized that it produced better results, and adopted it, not just for matters of science education, but across the board. What began as an operating premise produced a cultural transformation in the four districts.

\section{District Professional Learning Com-} munities. Distributed leadership brings different perspectives and more information into the decision-making and planning processes. Taken seriously, these shared experiences contribute to the development of a leadership community that learns. From the beginning of the Partnership, MISE's distributed view of district leadership was manifest in the requirement that each partner district establish a cross-role team to do the planning for the shared work and its organization and conduct of the Advisory Committee. These activities encouraged all participants to express their views, and differences in authority and power were reduced. The Advisory Committee itself provided a model for distributed leadership that the participants carried back to their districts.

Through these meetings and the local planning described below, the Partnership helped develop and strengthen networks of relationships within the districts that cut across the usual organizational hierarchy. The linchpins in these networks were typically the Partnership liaisons in each district who served as the key contacts for MISE, but they were supported by the cadres of Leader Teachers, especially those who served as instructors in the Partnership's professional development. As the Partnership advocates, the liaisons and Leader Teachers worked to advance the notion of distributed leadership. As the Partnership evolved and grew in strength, the liaisons, Leader Teachers, and other district administrators worked across district lines to support reforms in science and mathematics instruction.

Strategic Planning. MISE used strategic planning as a mechanism for focusing the attention of district leaders on the improvement of teaching, and for identifying problems, clarifying goals, developing coherent strategies to achieve goals, and tracking progress. They insisted on broad participation in the planning process. Each year, as part of their work with the Partnership, the districts identified goals and assessed their progress toward reaching them. In 1997, MISE staff asked the district teams to focus the strategic planning process on five areas: curriculum and instruction, professional development, student achievement and participation, district policies and practices, and parent and community support. Within each area, the districts were asked to define objectives and generate strategies for reaching them, to name the people responsible for the strategy, and to identify the resources and a timeline for reaching each objective. District teams were asked to make this planning process as inclusive as possible.

This was initially seen as "make work." After all, the districts had been submitting plans to state departments of education for years and generally ignored them once they were submitted. But this process was different. MISE staff worked with them on the plans, not only bringing expertise but also showing respect for the expertise of the local planning teams. And MISE took the plans seriously; they became the bases for the Partnership's activities. As local leaders began to see 
the impact of the activities on their teachers, and on their systems, they became more invested in the process.

In interviews, district leaders spoke about the value of the planning process to their districts. For example, one district leader described how strategic planning had provided a vision for the district:

The plan has given us a vision. Now our vision is "the sky is the limit." We now have a national, even international, perspective on what is possible. We have developed expertise in our district. We have had amazing access to some of the best people in the country. I feel so privileged to be part of this. It is the highlight of my own professional growth.

Another district leader described how the planning process had provided greater stability in the face of the constant changes in the district:

The strategic plan focuses us on what we need to do. We have a lot of new leadership in the district now, and the strategic plan helps us focus on the needs of the children even in the face of change. The plan gives us stability and focus in the face of change.

MISE's approach to strategic planning reinforced the concept of distributed leadership and contributed to gradual change in the norms of leadership in the four systems.

Problems of Leadership. The changes in leadership described above have had powerful effects, but they are also fragile. The four partner districts have experienced considerable turnover at the top. Twelve different superintendents have held office since 1994, three in each of the four districts. This could disrupt the work of the Partnership, but it did not because of Merck's status in the communities and the presence of strong professional communities supporting the work. The cultures of distributed leadership devel- oped through the Advisory Committee, the strategic planning process, and the strong support among teacher leaders served as pressures on new district leaders to not only support the Partnership, but to accept its strategies and norms. There also has been considerable turnover in the ranks of school principals. This has proved somewhat more disruptive to the work of the Partnership in the schools as not all of the new principals understood or supported the reforms, and they were not as quickly socialized into the culture surrounding the work. While principals received training in the early years of the Partnership, they were neglected for several years. This hampered the work in some schools. The Partnership has addressed this problem in recent years by offering a Principals' Institute that deepened principals' understanding and support, and brought new principals up to speed. It is clear that neglecting principals is costly and that they need to be regularly involved in any effort to improve instruction.

The development of teacher leadership also requires continued attention. The ranks of the original Leader Teachers have thinned over time due to promotions, departures to take better jobs, and retirements. While the local cultures have changed, providing more opportunities for teacher leadership, it is not clear that the districts have pathways for developing the next generation of teacher leaders. The attitudes of school principals toward distributed leadership could be a critical factor in the development of this next generation of teacher leaders and the Partnership has only recently begun to address this issue.

\section{Focus, Coherence, and Guidance}

One of the common characteristics of reforming districts is their focus, and their willingness and capacity to provide effective guidance about instruction. 
What are children expected to know and be able to do? How do policies support these goals? Effective districts are able to answer these questions. They know where they are trying to go, and they have a strong and sustained focus on getting there. In 1993, the four partner districts did not have coherent approaches to improving teaching, and science was not a priority. These conditions have changed. CPRE has tracked the policy changes in the districts, and through interviews with district leaders, identified some of the factors that helped them become more focused. A major part of the explanation lies in the changes in leadership described in the previous section, but MISE's strong commitment to a standards-based approach to reform and to aligning policies, programs, and practice with standards are also important parts of the story.

One of the major premises underlying MISE's systemic approach to school reform is that aligning key district and school policies with the goals of reform has a powerful cumulative effect on classroom practice. The logic goes as follows: When district policies send clear and consistent messages to teachers about priorities and best practices, these messages are more likely to be understood, accepted as legitimate, and acted upon. Conversely, failure to align policies produces inconsistent, confusing messages, and practitioners may respond differently, attending to the most pressing policy message or simply ignoring the guidance altogether. Clearly, the chances of making significant changes in classroom practice would be enhanced if local policies were aligned with the Partnership's vision of classroom practice.

In 1993, the first step that MISE took was to direct the attention of district leaders to the emerging content and performance standards in science. MISE used the national and state standards as the basis for helping the districts select new curricular materials and, later, for the development of curriculum frameworks. Standards were the underpinning of the professional development offered to teachers, and the development of the performance assessments. MISE staff also took a lead role in helping state officials develop science standards and new assessments. Standards provided the foundation for the work of the Partnership, and were embedded in all of its activities. Over time, standards became an integral part of the districts' approach to teaching and learning.

MISE also pushed the districts to consider standards for teaching. MISE's vision of good science teaching implied a set of standards and these were articulated and elaborated through the work of the Partnership. They were embedded in the curriculum frameworks, they shaped the observation training provided for principals, and they were the basis for revisions to local teacher observation systems.

When the policies and practices of the four districts in 1993-1994 are compared with those in force in 2002, the progress made in institutionalizing the reform vision is apparent. However, the process of change was gradual, and never heavyhanded. MISE focused on changing the norms of the leadership group, and supporting and guiding the professional communities that were created through the work of the Partnership. They expected superintendents and boards to recognize the need to change local policies, and did not directly pressure them to do so. Instead, they developed a climate in which policy changes were inevitable. When interviewed by CPRE in 2000, the superintendents of the four partner districts contended that the Partnership had not directly changed district policies, but they acknowledged that it had influenced district policies significantly. When one superintendent was asked if district policies had changed as a result of the Partnership, he answered: 
Indirectly. We have not changed one policy in writing to accommodate MISE's needs. That's not a bad thing. We haven't come across any conflicts. In the area of professional development and the release of staff to go to different things, we send groups of teachers to national science and math conventions. That's an indirect influence. We have expectations that what we plan in house should rise to the standards of MISE. It's a great example of homegrown reform...it could be replicated across the country.

When asked if MISE had influenced policy, another superintendent said, "I heard just last month from a [board] member, 'One thing we don't want to do is reduce professional development.' That's a big policy change in this district." The superintendent reported that just a few years back, some board members had strongly objected to the notion that teachers need to be "taught."

The science curricula in the four districts are now aligned with national and state standards. The local officials see their curriculum frameworks, materials selection processes, and curriculum-based professional development as keys to sustaining the vision and as major facilitators of instructional reform. All four districts have developed system-wide procedures for adopting science materials for K-8 classrooms that ensure alignment with standards and state assessments. Generally, they have become more deliberate and thoughtful about adoptions of instructional materials.

Another area in which there has been a "policy" change is teacher recruitment and hiring. One district leader said:

When we interview people, we ask them, "What do you know about inquiry-based instruction, inquiry-based [teaching], performance-based [assessments]? Are you willing to come to training?" We get questions from applicants: "What kinds of professional development can I get?" New teacher orientation used to be a one-hour meeting in the library. Now it's a weeklong training, science training, technology training, and district orientation. We want to expand it to language arts. The orientation changes are a result of the MISE Partnership.

Leaders in all four districts are paying more explicit attention to the mathematics and science skills of candidates for teaching positions. They now require new teachers to attend summer orientation workshops that include training in the inquiry approach, and all four districts encourage newly hired teachers to attend PTWs conducted in the summer before they take their new positions. Three of the districts report strengthening their support for new teachers.

Problems of Focus and Coherence. It is probably not reasonable to expect the partner districts to maintain a strong focus on science instruction year after year. Faced with resource constraints and competing demands, districts must make choices between investments in improving teaching in science or improving instruction in literacy, mathematics, or some other field. What can be hoped for is that science will get its fair share of attention and that the strategies that have proved successful in science will be replicated in other curriculum areas. So far, this appears to be the case.

It is also hard to focus on long-term improvement in the current chaotic policy environment. New state assessments are coming in literacy and mathematics along with the more stringent sanctions of No Child Left Behind. Districts and schools will be concerned about short-term gains in these tests because of the strong sanctions for failure to meet annual targets. Only time will tell if the focused strategies for improving teaching that characterized the Partnership will endure in this environment or the districts will revert to searches for quick fixes. 
Instructional Resources and Tools

One of the key findings from the research on effective districts is that these systems ensure that teachers have the resources and tools needed to carry out the envisioned reforms in practice. Indeed, providing employees with resources that reflect and reinforce the desired norms of practice is a powerful way for organizations to diffuse reforms. This has also proved to be true in the partner districts.

With support from MISE, all four districts adopted new instructional materials and systems for managing these resources in K-8 science. MISE's commitment to curricular change has included assisting districts with the purchase of additional instructional materials. Table 3 shows the increased use of standardsbased and inquiry-centered science modules over the life of the Partnership. By 1998, all K-6 teachers in the partner districts were expected to teach at least two inquiry-centered science modules each year, and, by 2001, they were all teaching at least three. Since, in most cases, the modules had to be checked out to be used, and had to be replenished once used, supervisors could tell if they were actually being used.

The continued evolution of these modules and the addition of new ones means there will be a continuing need for the kind of intensive in-service that the Partnership has provided for teachers.
Through this focused, curriculum-based training and good on-site support, teachers who lack strong science backgrounds are helped to make good use of these curriculum materials and offer their students opportunities to engage in scientific inquiry. All four districts report that all teachers are using the designated instructional materials for science and, therefore, science is now being taught in all elementary classrooms. Thus, a major step has been taken toward MISE's original goal of demonstrating that all students could become scientifically literate.

Inquiry consumes materials, and the science modules have to be replenished. All four districts reported that they had increased their expenditures on instructional materials in science. In 2000, one of the districts reported budgeting $\$ 30$ per student for instructional materials for science and mathematics. All districts have adopted specific procedures for replenishing the materials in the science modules. They now provide whatever is needed for teachers to make full use of the science modules and they equip new classrooms with the necessary materials.

Time Allocations. Materials are not the only resource that was affected by the Partnership. Instructional time, the most critical resource districts allocate, has also been affected. The districts have adopted explicit policies about the amount of time devoted to science. One allots $300 \mathrm{~min}-$ utes weekly for mathematics in elementary schools and 120 minutes for science. Another requires a minimum of $65 \mathrm{~min}$ -

\section{Table 3. Comparisons of K-6 Science Modules Used District-wide, 1994-1995 and 2002-2003}

\begin{tabular}{lccc}
\hline District & $\begin{array}{c}\text { Number of } \\
\text { Modules } \\
1994-1995\end{array}$ & $\begin{array}{c}\text { Number of } \\
\text { Modules } \\
2002-2003\end{array}$ & Percent Increase \\
\hline Linden & 21 & 28 & $33 \%$ \\
North Penn & 14 & 26 & $86 \%$ \\
Rahway & 8 & 26 & $225 \%$ \\
Readington & 14 & 25 & $79 \%$ \\
\hline
\end{tabular}


utes daily for mathematics and 150 minutes a week for science. These allotments reflect a dramatic change from 1993 when the time devoted to science was left to the discretion of individual teachers and varied from no time at all to three or four hours a week.

Tools for Improvement. The Partnership has also provided teachers with other tools for improving their practice, ranging from rubrics for assessing student work, to performance assessments linked to particular modules, to specialized science equipment accessible through the MISE Resource Center.

Problems with Resources. Even welldeveloped systems for providing teachers with good instructional materials cannot guarantee universal use. While CPRE's interviews with teachers revealed increasing levels of use of the science modules over time, even in 2001, a few teachers continued to resist using them. More importantly, use of the modules did not guarantee the use of inquiry in the classrooms. While most teachers had adopted inquiry methods and were becoming more adept in their use of them, some found this approach to be too difficult or threatening because of their inadequate science backgrounds. Significant numbers of teachers failed to distinguish between inquiry and hands-on activities in which students simply followed directions.

And there is some concern that in a period of tight budgets, the districts will not be able to maintain the modules as they have in the past. Expenditures for instructional materials, like expenditures for professional development, are often among the first cuts to be made when districts are faced with inadequate revenues.

The story of curricular change in the Partnership runs deeper than merely adding new science modules. State science standards are also influencing curriculum choices as the districts assess whether the currently used modules are aligned with the evolving vision of the state. Changes in the state science assessment resulting from No Child Left Behind also will influence these decisions. Given these factors, it will not be surprising if what is taught changes in varying degrees across the grades. Hopefully, this will simply mean adjustments in how the current modules are used or the addition of new standards-based modules that promote inquiry, but performance on the new tests and fiscal conditions may affect how the districts respond to the new demands. Lack of funds may make it difficult to replace modules, and a factoriented state assessment could drive many teachers to seek the security of a textbook.

\section{Support for Teacher Learning}

Research and common sense support the notion that teacher quality - what teachers know and can do - matters, and that district investment in, and commitment to, teacher learning are critical to the improvement of performance. Teachers' knowledge of subject matter, pedagogy, and their dispositions toward their students affect the efficacy of their instruction and the engagement and learning of their students. Effective districts recognize this, and provide well-designed supports for continued learning and improvement of practice.

The Partnership has altered the scope and nature of professional development in the four districts. Table 4 portrays the scope of the work in science. The reader should bear in mind that the districts were also making large investments in literacy and mathematics. The slight reduction in enrollments in the summer of 2002 may reflect the shift of work in mathematics to other funding sources as the NSF funding came to an end. MISE has continued its support for professional development in science and the districts 
have committed their own funds to continuing the summer work and to providing follow-up support in the schools. All four districts offered PTWs in the summer of 2003. This approach to professional development has been highly effective at changing practice and at building professional communities in and across schools that engage teachers in continued learning (Corcoran, McVay \& Riordan, in press).

Almost without exception, district leaders and staff from all four districts praised the Partnership's commitment to quality, and said that the duration, scope, and focus of the professional development was unprecedented in their experience. But the Partnership had done more than simply provide good professional development. By involving local staff in the planning and delivery of the professional development and shifting increasing responsibilities to the districts over the years, it profoundly affected their vision of good professional development and their capacity to provide it. In 19941995, the Partnership's professional development was largely planned and delivered by MISE staff and external educators. By 2000-2001, the districts were in the lead and most of the trainers and facilitators were recruited from their own teaching staffs.

Leaders in all four districts felt that they now had the capacity to plan and deliver high-quality professional devel- opment on their own. While they used MISE staff and external experts occasionally, they relied primarily on their own teaching staff to provide professional development for their teachers. While only one of the districts had designated staff development specialists, leaders in all four districts felt that they had numerous staff members with the requisite knowledge and skill to design and lead professional development.

Standards of quality and expectations for professional development had changed. One district leader described teachers' raised expectations for professional development:

They've [teachers] all become critical consumers. Before, it was almost expected it [professional development] would be boring. You now know what good, highquality professional development looks like. You participate, you're an active participant. They [teachers] demand more now. And they've become more vocal. The day of accepting just a lecture is almost over.

A district official from another district said the "...days of gurus and entertainers were over...Teachers expect professional development to be practical and to build on what they know."

MISE continues to work with the districts to support their professional development, but the locus of action and

Table 4. Peer Teacher Workshops, 1996-2002

\begin{tabular}{lcccccc}
\hline Year & $\begin{array}{c}\text { Number } \\
\text { of PTWs }\end{array}$ & $\begin{array}{c}\text { Math } \\
\text { PTWs }\end{array}$ & $\begin{array}{c}\text { Math and } \\
\text { Science }\end{array}$ & $\begin{array}{c}\text { Science } \\
\text { PTWs }\end{array}$ & $\begin{array}{c}\text { PTW } \\
\text { Enrollment }\end{array}$ & $\begin{array}{c}\text { Number of } \\
\text { Individuals }\end{array}$ \\
\hline Summer 1996 & 6 & 0 & 0 & 6 & 169 & 169 \\
Summer 1997 & 8 & 2 & 0 & 6 & 195 & 195 \\
Summer 1998 & 22 & 8 & 1 & 13 & 506 & 287 \\
Summer 1999 & 36 & 9 & 1 & 26 & 525 & 386 \\
Summer 2000 & 32 & 9 & 2 & 21 & 667 & 490 \\
Summer 2001 & 37 & 12 & 1 & 24 & $536^{\star}$ & $394^{\star}$ \\
Summer 2002 & 25 & 0 & 0 & 25 & 581 & 361 \\
Total & 141 & 40 & 5 & 96 & 2,598 & 1,921 \\
\hline
\end{tabular}

* Includes estimated enrollments in locally sponsored math PTWs.

Source: CPRE (2002, p. 19) 
responsibility has shifted. One consequence of this shift has been the development of strong local commitment to continue this work. Another is the transference of the strategies and practices into work in other areas of the curriculum. For example, the model of deliberate, wellplanned, intensive, continuous, and curriculum-related professional development is now being used in literacy. Three of the districts described how this approach had been applied to other subject areas.

Problems of Teacher Learning. As good as the Partnership professional development has been, and as extensive as it has been, questions remain about whether it is possible to prepare elementary teachers with weak science backgrounds to lead inquiry in their classrooms. There is no doubt that in the vast majority of classrooms, the teaching of science has improved as a result of the Partnership's activities. But in some classrooms, activity is confused with inquiry and the quality of the science content is problematic. Some teachers may have such weak science backgrounds that the benefits derived from professional development are limited. One solution to this problem is to change hiring policies and practices, and all four districts have taken steps in this direction. Another solution is to use science specialists earlier in the grade span, and one of the four districts has moved in this direction. This is a real problem that needs further attention. Good professional development and better materials may not be an adequate solution to the problems of poorly prepared elementary teachers.

\section{Changes in Professional Cultures}

The fourth critical aspect of an effective district concerns how professional culture influences and shapes the work that adults do with each other and with children. Simply put, this is how people in the organization understand the rules or norms that govern their behavior, their roles and responsibilities, and their relationships with each other and with the children and parents they serve. In the most effective districts, there is agreement about standards of practice, practice is public, and there is opportunity for discussion and reflection about practice. Professionals pay attention to data about student performance and evidence about instructional strategies, and they take responsibility for the results that are obtained, and work together to improve their practice.

Here too, CPRE has observed and documented profound change in the partner districts. The most critical changes concern teachers' attention to science, development of consensus on the norms of classroom practice, the willingness of teachers to improve their practice, and the willingness of the districts to support these efforts. The increased respect shown for the clinical expertise of teachers and the expectation that they should be consulted in the design of policies and programs and changes in district leaders' perceptions of how teachers learn have contributed to these cultural changes. So too, have the collegial cultures of the summer workshops and the study groups fostered by MISE.

A Focus on Science. All of the data presented above offer proof that the four districts have had a strong focus on science. There is considerable evidence that science is now regularly taught in almost all, if not all, classrooms in the four districts. The teacher and principal surveys show this to be the case, and random observations and interviews conducted by CPRE confirm it. The districts' expenditures on the summer PTWs and on science materials demonstrate it. Teachers' continued demand for the summer institutes shows that many of them have developed a strong interest in science and want to deepen their knowl- 
edge. As one administrator put it, "Science is now a basic; teachers realize that it is important for children to develop the thinking skills that come with studying science."

Consensus on Good Practice. District officials interviewed by CPRE felt that MISE's persistent attention to standards had paid off, and that almost everyone had accepted the content standards for science and the standards for teaching. Inquiry had gained broad acceptance as the best approach to teaching science. Again, both survey and interview data confirm this assessment. In interviews, district leaders and principals provided examples of how teachers have adopted inquiry methods as a result of their participation in Partnership activities with MISE. One individual described changes in the look of classrooms:

Kids don't sit in rows facing the teacher. They sit in groups of four; there's cooperative learning. There's more movement in class. Classroom management has become [better] because there's more movement.

Another district individual noted the differences in science classes:

Before, teachers might have done a demonstration, kids watched, or all kids did the same science project. The text is not the focus anymore. It's inquiry-based. Kids are constructing their own lessons. It's hands-on. It's fun for the kids. Science didn't come alive [before].

A third district individual commented on the changes in teachers' confidence as science teachers as a result of their experiences. In turn, teachers' increased confidence has led to changes in science classes, both in pedagogy and curriculum development. She said:

The amount of teachers' energy and their confidence to teach science. They're not afraid to touch animals. That's great!
They've given up some control and they're not afraid to do it.

There was general agreement that teachers' thinking about science and about their practice had changed significantly as a result of their experiences with MISE. Moreover, central office staff believed that these changes in teachers' thinking reflected deep changes in classroom practices. Those interviewed admitted that the process had been slow and difficult, and acknowledged that changing practices was "hard work." Moreover, most district staff believed that these changes were deep, permanent, and had become part of the school fabric. As noted above, they perceived profound changes in attitudes. Describing these shifts in attitudes as "cultural changes," one district person said:

Teachers are now willing to go to meetings without pay. The reward is intrinsic, not extrinsic. A change has occurred in the culture. It's now okay to talk about science.

Another district individual said, "Practices have changed. What teachers have learned will stay with them." A superintendent phrased it more powerfully, "Teachers who have been through MISE have changed forever."

Problems in the Professional Culture. The problems of maintaining a focus on science as new policies are handed down and of getting all teachers to use inquiry methods have already been discussed. One further obstacle to building strong professional cultures that preserve and communicate the norms of practice is that conditions vary across schools. The management styles and priorities of principals vary, and therefore the opportunities for teachers to collaborate and reflect on their practice also vary. Teacher expertise is not equally respected in all schools, and therefore teachers do not exercise the same influence over policies affecting teaching and learning. This is a 
problem that can be addressed through recruitment, supervision, and training of principals. To some extent, the continued presence of the Leader Teachers, teachers who have been involved in planning and delivering the PTWs, and "helping" teachers in science compensates for the variations in principals' attitudes and support.

The presence and penetration of the Partnership also varies considerably from school to school, and it changes over time due to retirement and mobility. One indicator of penetration is the percentage of teachers in a school who have attended summer PTWs. The level of participation varies across the elementary schools from less than $20 \%$ to over $90 \%$. In most of the Partnership's 34 schools, more than twothirds of the teachers have attended summer programs and have been trained in inquiry and exposed to norms of collaboration and reflection, but in a handful of schools, this is not the case. Moreover, as new teachers are hired and the composition of the staff changes, the norms of good practice will have to be refreshed through professional development. All four districts currently offer summer induction programs for new teachers that include an introduction to inquiry-centered teaching in science. Continuing to improve practice will require a sustained effort on the part of the districts to introduce new teachers to the norms of practice and bring them into the professional communities that support continued improvement.

\section{Attention to Data and Evidence}

The sixth and final area of district policy and practice examined here concerns the use of data and evidence. Researchers have shown that effective districts pay attention to data and use it at all levels to set priorities and to revise what they are doing. Continuous improvement requires attention to results, and that requires data.
MISE emphasized careful attention to data in the strategic planning process, and specifically worked with the partner districts to improve the quality of the achievement data in science available to the districts. MISE also funded the CPRE evaluation and used the feedback from the research team. The evaluation produced data on teachers' responses to professional development, changes in practice, and the relationship between changes in practice and student performance in science. The observations, findings, and recommendations of the CPRE team were published in annual reports, and shared with the district planning teams. From 1995 to 2002, CPRE issued eight annual reports that contained recommendations to MISE and the Partnership. Throughout this period, over 30 recommendations were offered, and most of them resulted in actions. Advisory Committee meetings were used to examine, reflect on, and interpret the data produced by CPRE.

MISE also modeled the use of research evidence in decision-making through its approach to designing professional development, by sharing the evidence about their design principles with all of the involved district staff, and in its review of instructional materials.

The most critical data set - indicators of student achievement in science proved to be a continuing problem for the Partnership. Originally, it was believed that a state assessment in science would be developed in New Jersey by the mid1990s and would provide the reliable outcome measures that the Partnership wanted. However continued delays in the development of this assessment led MISE and CPRE to persuade the districts to adopt the Stanford-9 (SAT-9) science assessment in 1996. Unfortunately, the districts chose to adopt only the openresponse items and not the entire science test, which included multiple-choice items. This made student-level results less reliable and there also was concern 
about the alignment of the open-ended items with the curriculum used in the partner districts. One of the district's science supervisors reflected this sentiment: "Just the Stanford-9 doesn't give you a good picture, it's just a snapshot. Teachers say, "The kids know more than they are able to show in a one-period assessment that doesn't really reflect what is being taught in their classrooms.'" The districts never embraced the SAT-9; it was seen as extra testing and was known as the Merck test or the CPRE test. It was often poorly administered and many students did not take it seriously, making it hard to get meaningful results.

In 1995, MISE began work to improve the quality of classroom assessments. A three-year project with consultants from the Educational Testing Service (ETS), working with Leader Teachers, produced a set of teacher-developed performance assessments that could be used in classrooms along with the science modules to inform instruction. This work culminated in the 1999 release of an Assessment Sampler, which contains tested assessments and is a resource for elementary school teachers, administrators, and staff developers. While the ETS/MISE assessment project provided an excellent professional development opportunity for the teachers involved and produced a variety of assessments for use by teachers, MISE staff recognized that these products would not satisfy the needs of those audiences that expected the Partnership to provide data on the effects of its work on student performance.

These concerns led to the development of a multi-component Partnership Assessment Plan. The components included:

- A nationally validated standardized instrument that focuses on central themes in science to be given in grades 5 and 7.
- A "middle ground" set of standardized hands-on performance assessments in grades 3 and 7 that are not tightly linked to the curriculum in the Partnership districts.

- A series of pre- and post-assessments that are based on the science modules used in the Partnership districts.

- Teacher-developed, non-standardized assessment items that are used primarily to inform instruction.

MISE and the partner districts decided to review the alignment of the SAT9 with the New Jersey science standards and to consider alternatives, recognizing that they would sacrifice the capacity to conduct longitudinal analyses if they replaced the SAT-9. Based on this review, the SAT-9 science test was abandoned in 2001, and three of the partner districts subsequently adopted the TerraNova science test. Additionally, New Jersey began its own statewide science assessment in grades 4 and 8 in 1999 and 2000, respectively. Unfortunately for the Partnership, the fourth-grade state assessment was abandoned in 2003 as a result of the state's need to meet the requirements of No Child Left Behind.

To implement the second and third components of the Partnership Assessment Plan, MISE developed a PTW on assessment and hired one of the researchers from TIMSS to assist with it. In the summer of 1998, this researcher introduced a variety of TIMSS performance assessments to teachers from all four districts, and the group selected two performance tasks for third graders and two for seventh graders. Although the group considered modifying these tasks, they decided to use them as they were used in the TIMSS study so that national and international comparisons could be made. In the fall, the TIMSS tasks were piloted with a sample of third- and seventh-grade students across the Partnership, and the members of the PTW 
met to score the students' work. The TIMSS performance tasks have been administered district-wide in grades 3 and 7 since the spring of 1999 and have been used by teachers and schools as another measure of their instructional effectiveness.

Problems of Data. Administrators and teachers in the four partner districts have become more sophisticated users of data by working with MISE on strategic plans and on the performance assessments. But use requires access to good data, and good assessment takes time and money, and these are scarce resources. So the primary problems in this domain are the obvious ones. These issues complicate the problem of finding or developing science assessments sensitive to the effects of inquiry and also providing reliable measures of growth and cross-site comparisons. Such assessments tend to be expensive and take time to administer and score.

If the new state assessment in science focuses on multiple-choice items and on science "facts" because this form of assessment is cheaper and can be scored more quickly, then the emphasis on inquiry will be threatened as the scores on tests may not adequately reflect what students are learning. The current $\mathrm{New}$ Jersey initiative to develop local performance measures may offer a remedy to this problem, but the capacity of the districts to sustain the instructional reforms achieved through the Partnership will be affected by the decisions made by state policymakers about assessment.

\section{The Bottom Line}

After nearly a decade of work with MISE, it is clear that the four districts have changed dramatically, that their capacity to support improvements in instruction has been significantly enhanced, and the impact has extended beyond science and mathematics. Return- ing again to the framework that we used earlier in describing the baseline conditions, we examine how some of the critical conditions in the districts were affected by a decade of partnering with MISE.

Focus, Standards of Practice, and Alignment. Science was not a priority in the elementary and middle schools in the four partner districts in 1993. It is a priority now. In the three New Jersey districts, this shift in focus is due in part to the development of state science standards and the addition of science tests to the state assessment program. However, the observed changes in the four districts have gone much deeper than simply preparing students for a new state assessment, and both administrators and teachers attribute these changes to the collaboration with MISE. The districts have developed and adopted new curriculum frameworks in science and mathematics, and the former are aligned with the Partnership's vision of inquirycentered science instruction. They have adopted science modules aligned with state standards for grades K-8, and have established procedures for the maintenance of these modules. Principals and central office supervisors now actively monitor curriculum implementation to ensure that the science modules are actually used. All four districts have strengthened assessments in science, and are participating in the performance assessments in grades 3, 4, 7, and 8 supported by MISE. Administrators in three of the four districts report that they now look at the science backgrounds of candidates for teaching positions, and try to hire individuals with strong science training. And all four districts continue to offer summer institutes in science and mathematics even though the NSF funding has ended and support from MISE has been reduced. Participation in these institutes remains high.

Perhaps most importantly, there is broad acceptance of inquiry as the pre- 
ferred instructional approach in science. The shared professional development experiences and participation in the shared work on professional development, curriculum, and assessment have led to the development of strong professional communities in science in, and across, the four districts that reinforce and sustain the new norms of practice. These communities also increase the likelihood that science will remain a focus. In addition, these new norms of practice are reinforced by the frameworks, the performance assessments, and the professional development.

Leadership. Distributed leadership also has been promoted through the work of the Partnership. Principals and teachers are regularly included in district planning and policy discussions - at least when science and mathematics are the focus - and their opinions seem to be valued. Accomplished teachers play leadership roles in professional development, curriculum, and assessment, and they feel that they have been empowered by the Partnership. While the influence exercised by teachers varies somewhat across the four districts, there has been considerable progress in all four districts.

At the school level, there is greater variation, and the roles played by the teachers are highly dependent on the management style of the principal and on the academic priorities in the building. However, teachers in over two-thirds of the schools describe their principals as highly supportive of their work in science, and an equal number say that their principals share decision-making with teachers. A higher proportion indicate that they have regular opportunities to work with colleagues on science. MISE has provided principals with opportunities for professional growth that helped them gain a better understanding of good practice in science and mathematics and what distributed leadership means in practice. One indication of the success of these efforts comes from a comparative analysis of interviews conducted with principals in 1994 and 2000. In the latter interviews, principals were more respectful of teacher expertise and more likely to indicate that they relied on teacher leaders to support improvements in teaching.

\section{Instructional Resources and Teacher}

Development. The Partnership has contributed to significant improvements in the science and mathematics curriculum in the four districts. Teachers have access to science modules and materials that were not available to them eight years ago. MISE staff have assisted district staff with selection of new instructional materials for science, development of curricular frameworks aligned to state and national standards, and design and development of professional development activities that support the new curriculum. Science modules designed to encourage and support inquiry form the backbone of the K-8 science curriculum in all four districts and are used by almost all teachers. While some teachers continue to use science texts, increasingly, the texts are being used as reference books to supplement the modules.

With some support from MISE, the districts are continuing to provide highquality professional development to support the implementation of their science and math curriculum and to deepen teachers' understanding of science and their ability to support and guide student inquiry. The four partner districts have not only learned how to provide high-quality professional development, they have learned how to provide it at considerable scale, and they have learned how to recruit high proportions of teachers to participate. Analyses of student performance on standardized tests reveal that students who have received science instruction over several years from teachers who have participated in the Partnership professional development outperformed students who have been taught by non-participants. 
These data suggest that, in the long run, as teachers continue to participate in the workshops, there will be a continued positive impact on student performance in science. Recognizing this benefit, the districts are eager to continue the relationship with MISE, but they also are investing their own resources in highquality, curriculum-based professional development.

New teachers receive an introduction to inquiry as part of their induction. Teachers in all four districts have access to in-school support in science from science supervisors and "helping" teachers and less formally from peers who have been active in the Partnership professional development. While the quality of the available support varies somewhat across the districts, and among schools within each district, most teachers in the Partnership schools can easily access assistance in science or mathematics from an experienced support person or a colleague.

Clearly, participation in the Partnership and collaboration with MISE has produced significant improvements in science instruction, and in mathematics as well, in the four partner districts. Many teachers have much deeper understanding of content and of effective teaching skills as a result of the intensive professional development and the Leader Teacher program offered over the past decade. Equally important, MISE has built considerable internal capacity for instructional support that will enable the districts to continue this work on their own.

Professional Norms and Use of Data. The norms governing the behavior of professionals have changed. Inquirycentered teaching has become the norm of good practice in science. The vast majority of teachers accept the responsibility for improving their teaching and regular participation in intensive professional development has also become a norm. Sharing lessons and materials, and discussing their effectiveness with colleagues, are common practices. Practice has become more public for many teachers, although the norm of privacy remains strong. The incidence of peer observation, co-teaching, and collective review of student work have been increasing.

There is a great deal more attention to performance data. The four districts are continuing the strategic planning process for professional development that MISE introduced, and this is helping them focus their investments in professional development and make better use of their resources. All four districts are participating in district-wide administration of performance assessments in science in grades $3,4,7$, and 8 , and the data are being used by teachers to reflect on their use of inquiry and their success in teaching key concepts. In classrooms, more teachers are using performance tasks developed to align with the science modules to see if students understand and can apply science concepts. The interest in, and use of, formative assessments to determine if key concepts are understood has steadily increased.

These changes are systemic, they are deep, and they are continuing. The collaboration with MISE has not simply moved the four districts from one steady state characterized by neglect of science and reliance on textbooks to another steady state characterized by use of modules and inquiry, it has also helped them become learning organizations. They have learned that intentional, thoughtful efforts to change practice can pay off, and they have the capacity to continue this work.

\section{Sustaining the Work}

What will be sustained from this decade of collaborative work to improve teaching? Will it be a higher priority on science and mathematics? Will it be the 
strategies that the partners have used to promote the development of teacher knowledge and communities of practice in science? Will these strategies transfer to other areas of the curriculum? Or will the pressures of increased accountability under No Child Left Behind shift their attention to test preparation? There are no clear answers to these questions, of course, and while we have described some of the potential threats to these reforms, there also are some reasons for optimism. Leadership in the four districts itself has been altered. Superintendents and principals are still in charge and held responsible, but they are accustomed to seeking advice from accomplished teachers, and to giving them leadership responsibilities. Those who now exercise leadership know what can be achieved by expanding leadership. They know what can be accomplished by sustained, focused work. The norms of leadership have changed, and there are articulate professional communities that support the Partnership's vision of teaching and learning in science. The districts also have adopted more coherent policies, and they have increased capacity for providing teachers with support. And, they are likely to be pressured by their own staffs to continue to offer high-quality professional development.

The majority of the district leaders and staff interviewed by CPRE felt that the changes that have occurred in attitudes, thinking, and practices were likely to be permanent. While a few individuals questioned whether these changes could be sustained once the formal Partnership ended, most felt that the changes were deeply embedded in the cultures of the organizations. While some worried about locating the funding needed to continue the kind of professional development that they had been providing, most felt that they could continue this work although perhaps on a smaller scale. Leaders in all four districts pointed to the use of teacher leaders, summer institutes, and on-site support in other curriculum areas as evidence that they would not return to past practice. A typical response was:

...perhaps we will not be able to offer as many Peer Teacher Workshops each summer or maybe we will offer science every other summer, but we will continue it because it works. Before MISE, we wasted money on professional development, and now we know how to make better use of what we have. And our teachers will demand it.

However, one more pessimistic individual said:

There's a level of anxiety I'm hearing [in the schools]. "When is this ending?"

"What will happen when it does?" I think that's one of the reasons the participation has increased... When it's over, it's over. We can teach them but we can't pay them, we can't feed them. It's known as the MISE workshop, not "the North Penn" workshop. It comes with things the district can't supply.

This pessimistic view was not shared by others in the same district. The superintendent said:

I don't want people to view MISE as a flash-in-the-pan. I think because it's been spread out over all these years, it won't be a flash-in-the-pan. Most schools focus year-to-year. If you focus on a project, it becomes part of the district.

At least one of the districts is planning for post-Partnership life by using the Partnership as a model to follow in building relationships with other corporate and industrial sponsors. Linden and Rahway anticipate that they will become more dependent on each other and that their continued collaboration will help them to sustain some of the Partnership's work.

Meanwhile, MISE is continuing to provide some support for the four districts, and in the first two years after the 
end of the NSF funding, there is little indication of any backsliding. One of the challenges facing the districts and MISE will be to monitor what takes place in order to determine what interventions, if any, are required to strengthen or reinforce the norms and practice that support continuous improvement of teaching.

\section{Lessons Learned}

So what can we learn from these four cases about the questions we posed at the beginning of this report? Can interventions be designed to improve the capacity of school districts to improve teaching and learning? Is it possible to alter the organizational capacities of districts by changing their organizational cultures and building their human, social, and physical capital? Can external organizations stimulate such transformations? Is the framework presented at the beginning of this report a useful guide to the design of such interventions?

We believe that the case of the MISE Partnership suggests the answers to these questions are all affirmative. The four districts are demonstration proofs that it is possible to intervene in rather typical school districts and enhance their capacity to improve teaching. They also demonstrate that changes in culture, human capital, instructional materials, and policies are all essential components of this work. What are the important lessons to be drawn from the successful experience of the MISE Partnership? They fall into two broad categories: lessons about the roles of reform support organizations and lessons about school districts.

\section{Roles of Reform Support Organizations}

MISE is a special type of organization, an organization created for the sole purpose of stimulating and supporting improvements in the teaching of science.
It has been effective because it has been able to play multiple roles, serving as a champion of reform, a political advocate for its vision, a technical assister, a training organization, a program developer, and a developer of leaders (McDonald, McLaughlin, \& Corcoran, 1999). These roles represent different ways to inspire vision, focus change, support change efforts, and press people to persevere despite the vicissitudes of the change process.

Champions of Reform. Reform support organizations often hold distinctive beliefs about school reform - like New York City's New Visions for Public Schools' belief in small schools or the El Paso Collaborative for Excellence in Education's championing of standardsbased instruction. MISE championed particular beliefs about teaching science and translated those beliefs into a series of actions that produced deep changes in professional norms, roles, relationships, and practices.

Why do school systems need intermediary organizations to champion reforms? School systems operate in highly complex and fragmented policy environments, and are under constant pressure for improvement and policy change from a variety of actors. Policies come and go as school, district, and state leaders change. Persistence and successful implementation of reforms are hard to achieve in this environment. Reform support organizations can help school districts stay focused. They can legitimate strategies and policies, build public support, and buy the time to make them work.

Reform support organizations can provide political help. Superintendents, school board members, mayors, state departments of education, governors and legislatures, local political interest groups, business and other civic leaders, community activists, parent groups, and others advance different reform priorities and 
strategies. Intermediaries often are able to shape the stakeholders' definition of the "problem" and build a more stable reform agenda. Unlike schools and districts, they are not subject to direct political authority and are more focused in their aims.

MISE helped its partner districts build community acceptance and support for the reforms in science because it could draw on the reputation of Merck as a company known for the quality of its scientific work. This reputation legitimated the investments made by the districts, and ensured that the work continued from one superintendent to the next. When board members questioned the emphasis on science or the investments in professional development, Merck could rally public support for the Partnership.

\section{Training and Assistance. Many} reform support organizations provide school systems with training and technical assistance in order to support the implementation of the reforms that they champion. However, few organizations attempt to transform how the district approaches professional development, and seek to engage so many teachers and to engage them repeatedly. Professional development was a central strategy for MISE and the Partnership, but it went beyond mere training to transmit a different vision of the capacity and responsibility of the professional teacher. It enhanced their knowledge of science and their pedagogical skills, but it also elevated their sense of professionalism and their sense of the possibilities of better outcomes. This was development of the profession as well as professional development. Altering the roles and expectations of teachers changes the cultures of the organizations and increases the likelihood that the reforms can be sustained.

Program Developers. Reform support organizations provide focus, support, expertise, and pressure for the creation of new and needed programs. However, they often are advocates for a particular program. MISE advocates the use of standards and a particular vision of science instruction, but it also modeled the use of evidence in selecting strategies, materials, and tools. MISE brokered access to new curriculum materials in science and new practices in assessment, and helped the districts develop criteria for deciding what to adopt. It helped the districts make good use of available materials, and helped them design the pieces that were not available. MISE has focused heavily on professional development for teachers in science, but it also collaborated with the partner districts to develop curriculum frameworks, develop and implement new performance assessments, and design leadership development for principals. The new norms of practice have been embedded in materials and tools that teachers use every day and help spread the acceptance of these norms and make them operational in practice. Having a partner with the capacity for search, design, and development is a valuable asset when a district is attempting to build widespread consensus about a new way of doing business.

Building Leadership. Reform depends ultimately on the quality of leadership at the school and district levels. Successful reform requires leaders who understand the problems and communicate vision about solutions that inspire and mobilize people. Reform also requires focus, support, and persistence, and reform support organizations can help.

MISE strengthened leadership in several ways: first, by providing local policymakers with a vision; second, by insisting that there be broad participation in planning and more collective decisionmaking; and third, by developing the confidence and capacity of teachers to act as leaders. And, of course, MISE itself provided leadership and MISE staff often took the lead in early stages of the work. 
This sense of collective leadership across the Partnership and within the districts protected the reforms from the turmoil surrounding changes in superintendents and boards.

Persistence. Perhaps MISE's greatest asset is the ability to stay focused on a specific set of objectives. Most reform support organizations are forced to alter their objectives to fit the whims of funders and to demonstrate that they can have broad impact. Thus, it is unusual to work with a district for more than threeto-five years. The support of Merck has provided MISE the opportunity to engage in longer-term partnerships. Given the time it takes to set up high-quality professional development opportunities, and evidence that it takes three years or more for teachers to make deep and lasting changes in their practice, it seems clear that most three-year projects are likely to fail to have lasting impact. We do not have a lot of data about how long it takes to change a school system and to build capacity to sustain instructional improvement, but District \#2 worked on literacy for a decade and the El Paso

Collaborative's work in three districts has lasted as long. Perhaps there is a lesson here for funders about expectations and the durations of partnerships with districts.

\section{The Role of Districts}

What lessons can we draw about school districts? First, districts can intentionally change classroom practice at scale, and they can, with some support, do this work well. It takes a long time, it is hard work, and it is always fragile and problematic, but it is exactly the work that school districts should be focused on. And this is exactly the work that the critics of the current governance and administrative arrangements in public education argue that districts cannot do.
The second lesson is that the research about effective districts has identified some of the essential attributes of district capacity and can guide reform support organizations and districts as they attempt to improve their performance. The framework arising from our review of the research on districts identifies eight big ideas: leadership committed to improvement of teaching, focus over time, coherent strategies and policies, the provision of adequate instructional resources, setting clear expectations about classroom practice, the development of teachers' knowledge and skills, the creation of professional norms that support improvement, and attention to data and evidence as key factors in improvement. The cases of the four MISE partners seem to validate this framework and our analysis has unbundled these eight domains to define them operationally and identify some of the mechanisms that explain how they link to instructional improvement.

We can only hypothesize from our data about whether each of the eight components in our framework have to be addressed for an improvement initiative to be effective or whether some are more important than others. Clearly, in the MISE case, focus and persistence were critical aspects of its strategy. And developing and engaging leadership, providing high-quality professional development, securing and allocating adequate resources, and developing communities of practice around a shared vision of good practice were also central strategies. Ignoring any of these elements would have undermined the Partnership and resulted in much less impact. However, MISE also addressed the other three elements, and while they were not always in the foreground, this work also contributed to their success. A key lesson may be that one should address all of these elements but around a central focus - in this case, science - so that their connectivity is obvious and addressed. A related lesson may be that the key to success is 
focusing directly on curriculum and instruction, and treating all of the other components as mechanisms for supporting the changes being sought in the classroom. Many reform support organizations and many districts focus on structural changes - teaming, houses, small learning communities, study groups - in order to improve teaching and learning, but do not directly address instruction.

A third lesson is that it is useful to have prestigious external partners, and important to know how to work with these partners. Merck's corporate reputation for high-quality scientific work and high ethical standards brings credibility to MISE's work in science education. Merck's corporate image and record of success have enabled the Partnership to raise difficult issues with district leaders and to push hard for change. This relationship with Merck increases the likelihood that the districts can continue to work on improving science teaching and that they will be able to sustain the reforms that they have implemented. The strategy offers a blueprint for other organizations that might form partnerships with school districts.

A fourth lesson is that making significant changes in the classroom requires long-term, sustained efforts on the part of districts and their partners. Teachers change their practice incrementally at first, and it takes time for them to develop both competence and confidence in new methods (Corcoran, McVay, \& Riordan, in press; Supovitz \& Turner, 2000). In addition to the professional norms of autonomy and privacy that obstruct planned change efforts, teacher mobility, high turnover in administrative personnel, and changes in district priorities and policies threaten reforms that have been put in place. Scaling up within and across schools is difficult because of the intensity of the work and the long time it takes to institutionalize it. Persistence and patience pay off.
The fifth lesson is about the importance of sustained, high-quality professional development. If one builds good professional development programs, teachers will come. The Partnership has learned that teachers will voluntarily take advantage of opportunities to learn and to improve their teaching practice - if the opportunities are seen as worthwhile (CPRE, 2000). Respect for teachers' professionalism, expertise, and experience results in a growing commitment by teachers to improvement. Participation in good professional development matters. The more professional development teachers receive, the more their classroom instruction resembles the vision of good practice advanced by MISE. It also appears that when a critical mass of teachers in a school has received professional development and begun to change their practice, the practice of non-participants also begins to shift in the same direction.

A sixth lesson is that capacity building takes careful planning and thoughtful collaboration. Rather than do for the school districts or give to the school districts, MISE encouraged them to look inward at their own human resources and to develop them. MISE helped them use the available resources to improve and then to build upon these successes. Of course, some funding was provided along with a great deal of technical assistance - but always with the consideration of how school leaders could own the work, and sustain and institutionalize the changes. When teachers train other teachers - and support and advocate for the reform efforts - local capacity is increased. MISE has leveraged resources and encouraged school district partners to do likewise.

Teachers' knowledge and skills are critical factors in the classroom learning experience, but not the only ones. The seventh lesson is that good curriculum materials and instructional tools are also essential. Teachers need access to, and support in, implementing standards- 
based curricula and teaching materials. MISE addressed these needs through its resource centers that made exemplary science education materials accessible for trials by teachers.

The final lesson concerns evaluation and evidence. The Partnership and MISE have invested in evaluation and made good use of the resulting feedback. CPRE has assessed the progress of MISE on an ongoing basis. Each year, after receiving feedback from CPRE and others, strategies have been revised to improve the work. However, better assessment tools in science are needed. Existing measures do not adequately show the effects of better science instruction. Right now, teachers see improved student work in their classrooms and a higher level of student interest in science, but the available measures do not adequately demonstrate this change to parents, school leaders, or the public. In addition to assessments that provide good diagnostic information for teachers' instructional planning, assessments must be persuasive to the public and policymakers as well.

It is not clear that policymakers will, or should, accept the notion that a 10year, well-funded effort to change conditions in four small-to-medium-sized districts is a model to be emulated. However, the intervention worked and some lessons might be drawn from this experience that could guide the design of less-costly interventions. And, if over the past 10 years, other organizations in $\mathrm{New}$ Jersey - foundations, corporations, colleges, non-profits - interested in school reform had followed similar strategies, we would have 50 to 100 districts with the capacity to improve teaching. Finally, these cases suggest an important role for reform support organizations as catalysts for the improvement of teaching and learning. 


\section{References}

Annenberg Institute for School Reform. (2002). Developing effective local partnerships to support local education. Providence, RI: Author.

Annenberg Institute for School Reform. (2003a). A district leader's guide to relationships that support systemic change. Providence, RI: Author.

Annenberg Institute for School Reform. (2003b). Reforming relationships: School districts, external organizations, and systemic change. Providence, RI: Author.

Argote, L. (1999). Organizational learning: Creating, retaining, and transferring knowledge. Boston: Kluwer.

Bacharach, S., \& Barnberger, P. (1995) Beyond situational constraints: Job resource inadequacy and individual performance at work. Human Resource Management Journal, 5(2), 79-102.

Berends, M., Chun, J., Schuyler, G., Stockly, S., \& Briggs, R. J. (2002). Challenges of conflicting school reforms. Santa Monica, CA: RAND.

Berends, M., Kirby, S. N., Naftel, S., \& McKelvey, C. (2001). Implementation and performance in New American Schools. Santa Monica, CA: RAND.

Bodilly, S. (1998). Lessons from New American Schools scale-up phase: Prospects for bringing designs to multiple schools. Santa Monica, CA: RAND.

Chubb, J. E., \& Moe, T. M. (1990). Politics, markets, and America's schools. Washington, DC: Brookings Institution.

Consortium for Policy Research in Education. (2000). Deepening the work: A report on the sixth year of the Merck Institute for Science Education. Philadelphia: Author.
Consortium for Policy Research in Education. (2002). A report on the eighth year of the Merck Institute for Science Education. Philadelphia: Author.

Corcoran, T. B. (1995). Helping teachers teach well: Transforming professional development (CPRE Policy Brief No. RB-16). New Brunswick, NJ: Consortium for Policy Research in Education, Rutgers University.

Corcoran, T. B. (2003). The Merck Institute for Science Education: A successful intermediary for school reform (CPRE Research Report No. RR-052). Philadelphia: Consortium for Policy Research in Education, University of Pennsylvania.

Corcoran, T. B., \& Goertz, M. E. (1995). Instructional capacity and high performance schools. Educational Researcher, 24(9), 27-31.

Corcoran, T. B., McVay, S., \& Riordan, K. (in press). Getting it right: The MISE approach to professional development. Philadelphia: Consortium for Policy Research in Education, University of Pennsylvania.

Darling-Hammond, L. (1993). Reframing the school reform agenda. Phi Delta Kappan, 74(10), 752-761.

David, J., \& Shields, P. (2001). When theory hits reality: Standards-based reform in urban districts. Menlo Park, CA: SRI International.

Elmore, R. F. (1993). The role of local school districts in instructional improvement. In S. H. Fuhrman (Ed.), Designing coherent educational policy: Improving the system (pp. 96-124). San Francisco: JosseyBass.

Elmore, R. F., \& Burney, D. (1997). Investing in teacher learning: Staff development and instructional improvement in Community District \#2, New York City. New York: 
National Commission on Teaching and America's Future, and Philadelphia: Consortium for Policy Research in Education, University of Pennsylvania.

Elmore, R. F., \& Burney, D. (1999). School variation and systemic instructional improvement in Community School District \#2, New York City. Pittsburgh: Learning Research and Development Center, University of Pittsburgh.

Firestone, W. A. (1989). Using reform: Conceptualizing district initiatives. Education Evaluation and Policy Analysis, 11 (2), 151-164.

Goertz, M. E., Floden, R., \& O'Day, J. A. (1995). Evaluating education reform: Systemic reform, Volume 1: Findings and conclusions (CPRE Research Report No. 035a). New Brunswick, NJ: Consortium for Policy Research in Education, Rutgers University.

Hess, F. (1999). Spinning wheels: The politics of urban school reform. Washington, DC: Brookings Institution.

Hightower, A. M., Knapp, M. S., Marsh, J. A., \& McLaughlin, M. W. (Eds.). (2002). School districts and instructional renewal. New York: Teachers College Press.

Hill, P. T., \& Celio, M. B. (1998). Fixing urban schools. Washington, DC: Brookings Institution.

Kirby, S. N., Berends, M., \& Naftel, S. (2001). Implementation in a longitudinal sample of New American Schools. Santa Monica, CA: RAND.

Kirst, M. W. (2002). Mayoral influence, new regimes, and public school governance (CPRE Research Report No. RR-049). Philadelphia: Consortium for Policy Research in Education, University of Pennsylvania.
Kronley, R. A., \& Handley, C. (2002). Reforming relationships: School districts, external organizations, and systemic change. Providence, RI: Annenberg Institute for School Reform.

Manpower Development Research Corporation. (2002). Foundations for success: Case studies of how urban school systems improve student achievement. Washington, DC: Council of Great City Schools.

Massell, D. (2000). The district role in building capacity: Four strategies (CPRE Policy Brief No. RB-32). Philadelphia: Consortium for Policy Research in Education, University of Pennsylvania.

McAdams, D. (2002). Fighting to save our urban schools - and winning: Lessons from Houston. New York: Teachers College Press.

McDonald, J., McLaughlin, M. W., \& Corcoran, T. B. (2000, April). Agents of reform: The role and function of intermediary organizations in the Annenberg Challenge. Paper presented at the annual meeting of the American Educational Research Association, New Orleans, LA.

McLaughlin, M. W., \& Talbert, J. E. (1993). Contexts that matter for teaching and learning. Stanford, CA: Center for Research on the Context of Secondary School Teaching, Stanford University.

McLaughlin, M. W., \& Talbert, J. E. (2002). Reforming districts. In A. M. Hightower, M. S. Knapp, J. A. Marsh, \& M. W. McLaughlin (Eds.), School districts and instructional renewal (pp. 173-192). New York: Teachers College Press.

Murphy, J., \& Hallinger, P. (1986). The superintendent as instructional leader: Findings from effective school districts. The Journal of Educational Administration, 24(2), 213-236. 
Murphy, J., \& Hallinger, P. (1988). Characteristics of instructionally effective districts. Journal of Educational Research, 81(3), 175-181.

National Commission on Governing America's Schools. (1999). Governing America's schools. Denver: Education Commission of the States.

Resnick, L. B., \& Harwell, M. (2000). Instructional variation and student achievement in a standards-based education district (CSE Tech. Report 522). Los Angeles: National Center for Research on Evaluation, Standards, and Student Testing, University of California-Los Angeles.

Riordan, K. (2003). Teacher leadership as a strategy for instructional improvement: The case of the Merck Institute for Science Education (CPRE Research Report No. RR-053). Philadelphia: Consortium for Policy Research in Education, University of Pennsylvania.

Rosenholtz, S. J. (1989). Teachers' workplace: The social organization of schools. White Plains, NY: Longman.

Rowan, B. (1996). Standards as incentives for instructional reform. In S. H. Fuhrman \& J. A. O'Day (Eds.), Rewards and reform: Creating educational incentives that work (pp. 195-225). San Francisco: Jossey-Bass.

Spillane, J. P. (1996). School districts matter: Local education authorities and state instructional policy. Educational Policy, 10(1), 63-87.

Spillane, J. P. (2002). District policymaking and state standards: A cognitive perspective on implementation. In A. M. Hightower, M. S. Knapp, J. A. Marsh, \& M. W. McLaughlin (Eds.), School districts and instructional renewal (pp. 143-159). New York: Teachers College Press.
Stein, M. K., \& D'Amico, L. (2002).

District as professional educator:

Teacher learning in District 2's literacy initiative. In A. M. Hightower, M. S.

Knapp, J. A. Marsh, \& M. W.

McLaughlin (Eds.), School districts and instructional renewal. New York: Teachers College Press.

Supovitz, J. A., \& Turner, H. M. (2000). The effects of professional development on science teaching practices and classroom culture. Journal of Research in Science Teaching, 37(9), 963-980.

Togneri, W., \& Anderson, S. E. (2003). Beyond islands of excellence: What districts can do to improve instruction and achievement in all schools. Washington, DC: Learning First Alliance. 


\section{Appendix A. Annual Reports on CPRE's Evaluation of the Merck Institute for Science Education}

The following evaluation reports are available by contacting (215) 573-0700, extension 1 or via email at cpre@gse.upenn.edu

Consortium for Policy Research in Education. (1995). The CPRE evaluation of the Merck Institute for Science Education. New Brunswick, NJ: Author.

Consortium for Policy Research in Education. (1996). Reforming science education: A report on the second year of the Merck Institute for Science Education partnership, 1994-95. Philadelphia: Author.

Consortium for Policy Research in Education. (1997). Scaling up reform in science education: A report on the third year of the Merck Institute for Science Education, 1995-96. Philadelphia: Author.

Consortium for Policy Research in Education. (1998). Expanding the breadth and effects of reform: A report on the fourth year of the Merck Institute for Science Education, 1996-97.

Philadelphia: Author.

Consortium for Policy Research in Education. (1999). A close look at effects on classroom practice and student performance: A report on the fifth year of the Merck Institute for Science Education, 1997-98. Philadelphia: Author.

Consortium for Policy Research in Education. (2000). Deepening the work: A report on the sixth year of the Merck Institute for Science Education, 1998-99. Philadelphia: Author.

Consortium for Policy Research in Education. (2001). Steady work: A report on the seventh year of the Merck Institute for Science Education, 1999-2000. Philadelphia: Author.

Consortium for Policy Research in Education. (2002). A report on the eighth year of the Merck Institute for Science Education. Philadelphia: Author. 


\section{Appendix B. Additonal Publications about the Merck Institute for Science Education}

The following publications are available by contacting (215) 573-0700, extension 1 or via email at cpre@gse.upenn.edu.

Consortium for Policy Research in Education. (2003). Systemic reform in practice: Merck Institute for Science Education. Philadelphia: Author.

Corcoran, T. (2003). The Merck Institute for Science Education: A successful intermediary for educational reform. Philadelphia: Consortium for Policy Research in Education, University of Pennsylvania.

Corcoran, T. B., McVay, S., \& Riordan, K. (in press). Getting it right: The MISE approach to professional development. Philadelphia: Consortium for Policy Research in Education, University of Pennsylvania.

Kannapel, P. J. (2003). Three Bridges and Holland Brook Elementary Schools, Readington Township, NJ. Philadelphia: Consortium for Policy Research in Education, University of Pennsylvania.

McVay, S. (2003). Franklin Elementary School, Rahway, NJ. Philadelphia: Consortium for Policy Research in Education, University of Pennsylvania.

McVay, S. (2003). Inglewood Elementary School, Lansdale, PA. Philadelphia: Consortium for Policy Research in Education, University of Pennsylvania.

Passantino, C. (2003). Highland Avenue School, Linden, NJ. Philadelphia: Consortium for Policy Research in Education, University of Pennsylvania.

Riordan, K. (2003). Teacher leadership as a strategy for instructional improvement: The case of the Merck Institute for Science Education. Philadelphia: Consortium for Policy Research in Education, University of Pennsylvania. 